\title{
Modelling of additive manufacturing processes: a review and classification
}

\author{
Panagiotis Stavropoulos ${ }^{*}$ and Panagis Foteinopoulos \\ Laboratory for Manufacturing Systems and Automation, Department of Mechanical Engineering and Aeronautics, University of \\ Patras, Patras 26500, Greece
}

Received: 6 October 2017 / Accepted: 21 November 2017

\begin{abstract}
Additive manufacturing (AM) is a very promising technology; however, there are a number of open issues related to the different AM processes. The literature on modelling the existing AM processes is reviewed and classified. A categorization of the different AM processes in process groups, according to the process mechanism, has been conducted and the most important issues are stated. Suggestions are made as to which approach is more appropriate according to the key performance indicator desired to be modelled and a discussion is included as to the way that future modelling work can better contribute to improving today's AM process understanding.
\end{abstract}

Keywords: Additive manufacturing / modelling / state of the art / process parameters / key performance indicators

\section{Introduction}

Additive manufacturing (AM) namely the process of joining materials for the production of objects, made of $3 \mathrm{D}$ model data, usually layer upon layer, as opposed to subtractive manufacturing methodologies [1] are applicable to a wide range of materials, including metals, composites [2] and even biomedical products [3]. AM [4] differs from rapid prototyping in the fact that AM specifically aims at the manufacturing of end user parts, rather than just prototypes [5]. The interest in AM processes has been steadily increasing in the last years and according to estimations it could exceed $5 \%$ of the total global market [6]. AM technologies have issues (Fig. 1) related to low productivity, poor quality and uncertainty of the final part's mechanical properties [7].

In this paper the AM modelling is classified according to key performance indicator (KPI), process parameters and the modelling approach/analytical, numerical or empirical [8]. For this study a classification [9] according to the process mechanism (ISO 17296-2) [10] has been followed (Table 2).

\section{Classification of modelling for AM processes}

In this section, the modelling approaches of each process group are classified according to the KPIs and the process parameters used. It has to be noted that the modelling

\footnotetext{
* e-mail: pstavr@lms.mech.upatras.gr
}

approach followed by some studies does not aim to the connection of the process parameters to the simulated KPIs. In such cases, the table cell referring to the process parameters is left empty, highlighting the KPI-centered perspective of those approaches. The most important issues of each AM process group are also described.

\subsection{Vat Photopolymerization processes}

The parts created through Vat Photopolymerization (VP), tend to have high dimensional accuracy and surface finish when compared with the majority of other AM processes. Moreover, the building time is an advantage of the VP technologies that use mask projection, in which an entire part cross section can be projected. The main drawback of the VP processes is their use of photopolymers, their impact strength and durability, which are inferior to those of good quality injection molded thermoplastics [11]. As a result, the main issue of the VP processes is that of the manufactured parts' mechanical properties and even though this is more an issue of the material type used, the optimization of the process, in terms of mechanical properties, can lead to improvements in this field. In Table 3 the process parameters and the KPIs of each modelling approach can be seen.

More specifically, the modelling works of VP focus on the topology and dimensional accuracy ([12-14] numerical) and mainly on the mechanical properties ([16] analyticalempirical, [17-21] numerical and [21-24] empirical) and finally in [25] an analytical-empirical approach models heat transfer related issues. 


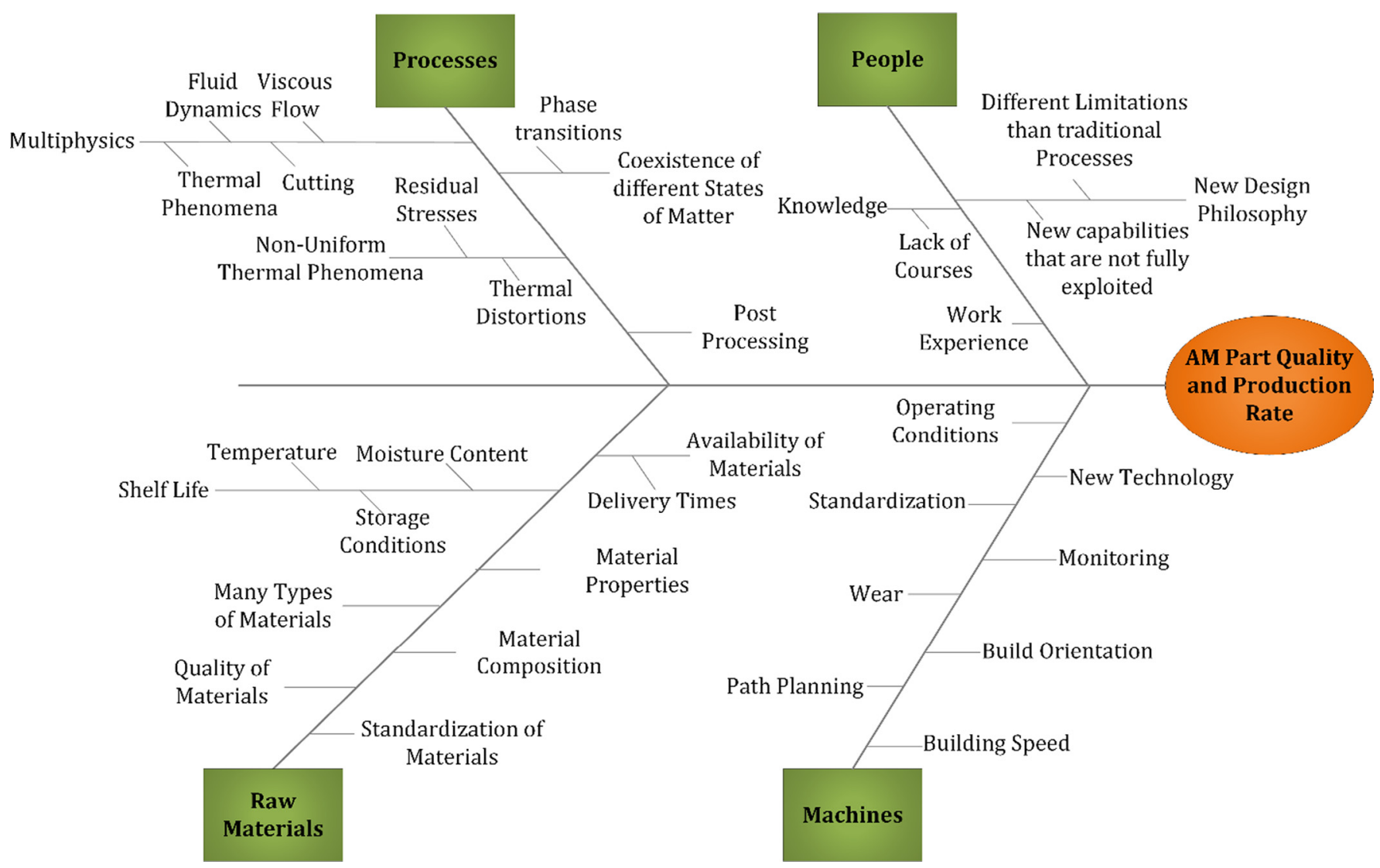

Fig. 1. Issues of AM.

\subsection{Powder bed fusion}

In the powder bed fusion (PBF) process group, there are four different fusion mechanisms: the powder particles are fused together with the use of solid-state sintering, chemically induced sintering, liquid-phase sintering or full melting [26,27]. In this study, the division among the PBF processes will be made in three subcategories in order to address not only the difference in the process mechanism (sintering and full meting), used by the most commercially available machines, but also the difference in the energy source (laser or electron beam). As a result, the three PBF sub-categories that will be used in the categorization of the existing studies, are the selective laser sintering (SLS), selective laser melting (SLM) and electron beam melting (EBM) process groups.

The high residual stresses that are present in the PBF AM processes, especially for metal manufacturing, lead to the warping of parts. In order for that to be minimized, techniques, such as the use of internal cooling channels, the careful selection of the part's orientation and the location of the supports have to take place. However, in order for that to be possible, the effects of the part's thermal history (residual stresses and thermal distortions) have to be taken into account. As a result, the modelling of thermal and thermo-mechanical phenomena, taking place in the PBF processes, are of crucial importance for the optimization of the processes. More specifically, the combination of the laser power, spot size and scan speed determines the fusion depth whilst the melt pool dimensions have a direct impact on the residual stresses of the parts. Powder shape, size and distribution strongly influence the laser absorption characteristics, as well as the powder bed density and powder bed thermal conductivity. As a result, those parameters have to be taken into consideration. Moreover, the selection of the laser-power and the bed-temperature play a crucial role in the dimensional accuracy, density, shrinkage and curling of the produced part, as well as in the recyclability of the unused powder. Consequently, all the above parameters have to be considered in the thermal modelling of those processes [11]. The different subgroups of the PBF family are described below.

\subsubsection{Selective laser sintering}

There are a lot of studies on the modelling of the SLS process, with an almost equal distribution among the various KPIs. In Table 4 the modelled KPIs and the process parameters that have been used in each study can be seen. Modelling of the topology/dimensional accuracy takes places in [28] (analytical-numerical approach), in [29-34] (numerical) and in [35] (empirical). Mechanical properties and microstructure modelling has been carried out in [30,36-41] using numerical approaches, whereas in [42] an empirical one has been followed. According to [43], the microstructure, physical and mechanical properties of the parts' being manufactured with the use of SLS, are fundamentally affected by laser power, laser scan speed and 
Table 1. Nomenclature.

\begin{tabular}{|c|c|}
\hline Abbreviation & Full name \\
\hline$\overline{\mathrm{AM}}$ & Additive Manufacturing \\
\hline ANN & Artificial Neural Networks \\
\hline BJ & Binder Jetting \\
\hline DED & Directed Energy Deposition \\
\hline DLD & Direct Laser Deposition \\
\hline DLP & Digital Light Processing \\
\hline DMD & Direct Metal Deposition \\
\hline DMLS & Direct Metal Laser Sintering \\
\hline DOE & Design of Experiments \\
\hline $\mathrm{EBF}^{3}$ & Electron-Beam Freeform Fabrication \\
\hline EBM & Electron Beam Melting \\
\hline FDM & Fused Deposition Modelling \\
\hline FFF & Fused Filament Fabrication \\
\hline KPI & Key Performance Indicator \\
\hline LBM & Laser Beam Melting \\
\hline LENS & Laser Engineered Net Shaping \\
\hline LMD & Laser Metal Deposition \\
\hline $\mathrm{LOM}$ & Laminated Object Manufacturing \\
\hline LPS & Liquid-Phase Sintering \\
\hline ME & Material Extrusion \\
\hline MJ & Material Jetting \\
\hline MJM & Multi-Jet Modelling \\
\hline PBF & Powder Bed Fusion \\
\hline PBIH & Powder Bed and Inkjet Head \\
\hline PMMA & Poly-Methyl Methacrylate \\
\hline $\mathrm{PP}$ & Plaster-based 3D Printing \\
\hline PSL & Projection Stereolithography \\
\hline SGC & Solid Ground Curing \\
\hline SHS & Selective Heat Sintering \\
\hline SL & Sheet Lamination \\
\hline SLA & Stereolithography \\
\hline SLM & Selective Laser Melting \\
\hline SLS & Selective Laser Sintering \\
\hline TAS & Total Area of Sintering \\
\hline UAM & Ultrasonic Additive Manufacturing \\
\hline $\mathrm{UC}$ & Ultrasonic Consolidation \\
\hline VP & Vat Photopolymerization \\
\hline WAM & Weld-based Additive Manufacturing \\
\hline
\end{tabular}

laser scan spacing. All of those parameters are directly related to the amount of energy imparted on the powder surface of the printed part. Build time has been analytically modelled in [29] and empirically in [44,45]. Energy consumption has been numerically modelled in $[33,47]$. Finally, most of the studies model heat transfer related KPIs either simultaneously with other KPIs $[28,30,32,40,41,46]$ or exclusively [48-54] and in either case using the numerical approach.
Table 2. Classification of AM processes.

\begin{tabular}{ll}
\hline AM Process Group & Typical commercial names \\
\hline Vat & Stereolithography, Digital Light \\
Photopolymerization & $\begin{array}{l}\text { Processing, Solid Ground Curing, } \\
\text { Projection Stereolithography }\end{array}$ \\
& \\
Powder Bed Fusion & Electron Beam Melting, Electron \\
& Beam Additive Manufacturing, \\
& Selective Laser Sintering, Selective \\
& Heat Sintering, Direct Metal Laser \\
& Sintering, Selective Laser Melting, \\
& Laser Beam Melting
\end{tabular}

Directed Energy $\quad$ Laser Metal Deposition, Direct

Deposition

Metal Deposition, Direct Laser

Deposition, Laser Engineered Net

Shaping, Electron-Beam Freeform

Fabrication, Weld-based Additive

Manufacturing

Binder Jetting Powder Bed and inkjet Head, Plaster-based 3D Printing

Material Extrusion Fused Deposition Modelling, Fused Filament Fabrication

Material Jetting Multi-Jet Modelling

Sheet Lamination Laminated Object Manufacturing, Ultrasonic Consolidation

\subsubsection{Selective laser melting}

SLM is a process similar to that of SLS; the two are instantiations of the same concept, but differ in technical details. In the SLM process for a part's formation, powder melting occurs instead of sintering. The modelling works, available in SLM, have a similar distribution to that of the SLS; in Table 5, summarization of the process, parameters and KPIs of the different modelling approaches can be seen.

More specifically, the surface roughness of parts has been modelled in $[55,56]$ by an analytical and a numerical approach respectively. In [31,32,57-61] topology and dimensional accuracy issues have been modelled using the numerical approach exclusively. In [62] mechanical properties and microstructure have been modelled analytically, whereas in $[56,63]$ numerically. Finally, most of the studies model heat transfer related KPIs either simultaneously with other KPIs [31,32,41,48,50,57-59] or exclusively [64-70] and in either case using the numerical approach.

\subsubsection{Electron beam melting}

EBM or EBAM (Electron beam additive manufacturing) has various advantages (high energy efficiency, high scan speed, moderate operation cost); however, process stabili- 
Table 3. Classification of the of the modelling studies on the VP AM process.

\begin{tabular}{|c|c|c|}
\hline $\begin{array}{l}\text { Reference } \\
\text { number }\end{array}$ & KPI & Process parameter (Variable) \\
\hline$[12]$ & Strain & Temperature \\
\hline$[14]$ & Deformation compensation & \\
\hline$[15]$ & Dimensional Accuracy & $\begin{array}{l}\text { Layer thickness, part position on the platform, } \\
\text { shrinkage compensation, retraction, hatch spacing, } \\
\text { alternate hatching, blade gap, stagger weave }\end{array}$ \\
\hline$[16]$ & Cure depth & $\begin{array}{l}\text { Penetration depth of UV radiation, scattering } \\
\text { coefficient }\end{array}$ \\
\hline [17-19] & Etching, deposition, lithography mechanics & Surface type, material, shape \\
\hline$[20]$ & $\begin{array}{l}\text { Tool strength, ejection forces, decision about the } \\
\text { quality of a tool according to the previous two }\end{array}$ & \\
\hline$[23]$ & Part strength (tensile, impact, flexural) & Layer thickness, post-curing time and orientation \\
\hline$[24]$ & $\begin{array}{l}\text { Tensile strength, crystallographic orientation- } \\
\text { density analysis }\end{array}$ & Layer thickness, orientation, hatch spacing \\
\hline$[25]$ & Energy distribution of a single pixel & Different types of stereolithography process \\
\hline
\end{tabular}

ty, part defects and quality variations are some issues that need to be improved [71]. In Table 6 , a summarization of the process, parameters and KPIs of the different modelling approaches can be seen.

In EBM, there is a limited number of the existing modelling publications, which focus almost entirely on thermal modelling [72], in which the analytical approach has been followed and $[32,41,49,50,73-77]$ via numerical methods. However, in [32] the residual stresses and distortions are also modelled using numerical methods.

\subsection{Directed energy deposition}

In the directed energy deposition processes (DED), the material deposition and melting are performed simultaneously. More specifically, energy is guided to a narrow focused region, where the substrate is melted, when heated by the power source (mainly laser beam), while at the same time, there is deposition of material which, as a result, is also melted [11]. The material can either be in wire or powder form. Most of the DED machines are very flexible concerning the process parameters' selection whilst the effects on many of them are strongly interrelated (powder feed rate, beam power, and traverse speed). In addition, their impact on the melt pool characteristics and on the thermal history determines the warping, residual stresses and the surface roughness of the parts [11]. Moreover, droplet kinematics, like in the MJ process group, play a major role here as well. The above references clarify the importance of modelling of the thermal history of a part, in which the laser power, scanning speed and melt pool characteristics are taken into account. Such studies can be utilized for the selection of the optimum process parameters, as well as for the optimization of the process itself, minimizing the need of expensive and time consuming experimental trial and error methodologies. The thermo-mechanical effects and especially the fluid dynamics have to be taken into account as well. In Table 7, a summarization of the process, parameters and KPIs of the different modelling approaches can be seen.

There is a plethora of modelling papers on the DMD process which are distributed, almost evenly, among the various KPIs. More specifically, modelling of surface roughness is presented in [78] (analytically) and in [79] (numerically). Modelling of topology and dimensional accuracy takes place in [80-84] using analytical, in [85,86] analytical-numerical, in [17-19,32,79,87-94] numerical, whereas in [95] those issues have been empirically modelled utilizing artificial neural networks (ANN). Modelling of the mechanical properties and microstructure has been conducted in [80,81] using analytical, in [86,96] analyticalnumerical and in [94,97-101] using numerical approaches. Droplet kinematics and flow phenomena have been modelled in [102,103] using analytical and in [87,98,104-113] using numerical approaches. Finally, heat transfer related KPIs have been modelled either simultaneously with other KPIs (in [114] analytically, in [85,86] analytically-numerically and in $[32,41,49,50,87,90-92,94,98,106,107,112]$ numerically) or exclusively ([115-118] numerically).

\subsection{Binder jetting}

Parts created by means of binder jetting (BJ), with plaster based powder and water based binder processes, tend to have low strength and stiffness. This is solved with the use 
Table 4. Classification of the of the modelling studies on the SLS AM process.

\begin{tabular}{|c|c|c|}
\hline $\begin{array}{l}\text { Reference } \\
\text { number }\end{array}$ & KPI & Process parameter (Variable) \\
\hline$[28]$ & Thermal deformations, heat transfer phenomena & \\
\hline$[29]$ & $\begin{array}{l}\text { Surface accuracy, build-time, orientation } \\
\text { efficiency }\end{array}$ & \\
\hline$[30]$ & $\begin{array}{l}\text { Length of the sintered piece, shrinkage depth, } \\
\text { temperature }\end{array}$ & Line energy, laser path \\
\hline$[31]$ & Residual stresses & Exposure strategy of the laser beam \\
\hline$[32]$ & Thermal modelling residual stresses, distortions & \\
\hline$[33]$ & Heat affected zone dimensions & Laser power, scanning speed, laser spot diameter \\
\hline$[34]$ & $\begin{array}{l}\text { Thermal modelling, absorption, sintering zone } \\
\text { dimensions }\end{array}$ & Scan speed, laser power \\
\hline$[35]$ & Shrinkage & $\begin{array}{l}\text { Laser power, beam speed, hatch spacing, part bed } \\
\text { temperature and scan length }\end{array}$ \\
\hline$[36]$ & Focal length, porosity of the powder bed & Shell thickness \\
\hline$[37]$ & Mechanical properties of the part & $\begin{array}{l}\text { Laser power, laser, beam velocity, hatch spacing, laser } \\
\text { beam spot size, scan line length, delay period, number } \\
\text { of effective, exposures }\end{array}$ \\
\hline$[38]$ & $\begin{array}{l}\text { Compressive effective stiffness, mechanical } \\
\text { properties in general }\end{array}$ & Porosity, hydroxyapatite loading, filler loading \\
\hline [39] & Modelling of the first stage of liquid phase & Capillary forces \\
\hline
\end{tabular}

[40] Fusion depth, temperature profile, degradation, Scan speed, laser power, powder types

[41] System temperature, microstructure

[42] Mechanical properties, part density

$\begin{array}{ll}{[44,45]} & \text { Build time } \\ {[46]} & \text { Thermal modelling, sintering depth, energy }\end{array}$

[46] Thermal modelling, sintering depth, energy
consumption

[47] Laser energy consumption

[48] Melting track profile, thermal modelling of particles

[43] Microstructure, mechanical properties

[49] Thermal modelling

[50] Part temperature history

[28,51] Thermal modelling, dimensional accuracy

[52] Thermal modelling

[53] Temperature of powder bed

[54] Thermal history

Laser power, scan spacing, scan speed, layer thickness, powder bed's temperature

Height, volume, bounding

Scan spacing beam diameter, wide range of other parameters

Part geometry, slice thickness, part orientation

Laser power, laser scan speed and laser scan spacing

Layer position in the part under construction

Laser power, laser speed, preheating temperature, laser beam diameter

Laser power, beam diameter, laser on-time, laser offtime, hatch spacing

of infiltrants, which greatly improve the material properties. Another strategy is the use of a poly-methyl methacrylate powder and a liquid binder that causes a curing reaction, at room temperature. In this case however, after the printing has been completed, the part has to remain in the build chamber for several hours in order for the curing to be completed. In order for metal parts to be manufactured, via the BJ process, a series of post processes is required. More specifically, three furnace cycles are necessary after the printing of a metal part, in order for the binder polymer to evaporate and the part's density to increase. This is achieved with the addition of extra metal ingots, being in contact with the part. Generally, the dimensional accuracy and the surface roughness of parts, made by BJ, are not as good as those made using MJ and they tend to have poorer accuracies and surface finishes [11]. These problems are mostly attributed to the inherent characteristics of the process; however, modelling and 
Table 5. Classification of the of the modelling studies on the SLM AM process.

\begin{tabular}{|c|c|c|}
\hline $\begin{array}{l}\text { Reference } \\
\text { number }\end{array}$ & KPI & Process parameter (Variable) \\
\hline$[55]$ & Surface roughness & Surface sloping angle \\
\hline$[56]$ & Porosity, roughness & Scanning speed, powder layer thickness, laser power \\
\hline [31] & Residual Stresses & Exposure strategy of the laser beam \\
\hline$[32]$ & Residual stresses, distortions & \\
\hline$[57]$ & Melt pool width & Scanning speed \\
\hline$[58]$ & Stress field, thermal history, & Laser scanning speed \\
\hline [59] & $\begin{array}{l}\text { Rate of temperature change, melt penetration/ } \\
\text { width, percentage of evaporated powder, build rate, } \\
\text { volume shrinkage }\end{array}$ & Distance from melt pool, laser power, scan speed \\
\hline$[60]$ & Track formation shape & Laser power, scan speed \\
\hline [61] & Melting, wetting, solidification & $\begin{array}{l}\text { Powder-layer thickness, moving heat source } \\
\text { intensity, scan spacing, scanning velocity }\end{array}$ \\
\hline [62] & Residual stresses, tensile stress & $\begin{array}{l}\text { Heating of base plate, heat treatment type, re- } \\
\text { scanning }\end{array}$ \\
\hline [63] & $\begin{array}{l}\text { Stiffness, yield strength, plateau stress, energy } \\
\text { absorbed, densification strain }\end{array}$ & Unit cell aspect ratio \\
\hline$[41]$ & System temperature & \\
\hline [49] & Heat transfer related & \\
\hline$[50]$ & Part Temperature history & Layer position in the part under construction \\
\hline [64] & Temperature, melt pool, liquid lifetime & Scan speed, laser power \\
\hline [65] & Width of the melt track, temperature distribution & Scan speed, laser power \\
\hline$[66]$ & Melting depth/width, temperature distribution & Scanning speed, laser power \\
\hline [67] & Absorbed lateral radiation & Beam shape characteristics \\
\hline [68] & $\begin{array}{l}\text { Effective thermal conductivity of support } \\
\text { structures, temperature }\end{array}$ & Volume fraction, number of cells \\
\hline [69] & Thermal modelling, melt pool shape characteristics & Evaporation, laser power \\
\hline$[70]$ & $\begin{array}{l}\text { Thermal history, melt pool dimensions, } \\
\text { computational speed }\end{array}$ & Laser power, scan speed, meshing size adaptation \\
\hline
\end{tabular}

Table 6. Classification of the of the modelling studies on the EBM AM process.

\begin{tabular}{lll}
\hline $\begin{array}{l}\text { Reference } \\
\text { number }\end{array}$ & KPI & Process parameter (Variable) \\
\hline$[32]$ & Residual stresses, distortions & \\
{$[41]$} & System temperature & \\
{$[49]$} & Heat transfer related & Layer position in the part under construction \\
{$[50]$} & Part Temperature history & Target material, accelerating voltage \\
{$[72]$} & Penetration depth, energy loss & Penetration depth, dissipated energy \\
{$[73]$} & Absorption coefficient & Beam power, beam scan speed \\
{$[74]$} & Thermal modelling, melt pool dimensions & Beam speed, beam current, beam diameter \\
{$[75]$} & Thermal modelling, melt pool dimensions & Acceleration, voltage, current, shape, beam gun \\
{$[76]$} & Thermal modelling & movements, exponential, constant absorption types \\
& & Scan speed, line energy \\
{$[77]$} & Thermal modelling, lifetime dimensions of the melt & \\
& pool &
\end{tabular}


Table 7. Classification of the of the modelling studies on the DED AM process.

\begin{tabular}{l}
$\begin{array}{l}\text { Reference KPI } \\
\text { number }\end{array}$ \\
\hline
\end{tabular}

number

[17-19] Etching, deposition, lithography mechanics Surface type, material, shape

[32] Residual stresses, distortions

[41] System temperature

[49] Heat transfer related

[50] Part temperature history

[78] Surface finish

[79] Surface finish, melt pool, dilution ratio

$[82,83] \quad$ Clad width, depth and height

[81] Track and microstructure formation

[84] Layer/melt pool dimensions

Layer position in the part under construction

Melt-pool geometries, layer thickness, powder/laser interaction distance

Laser power, scanning speed, and powder feed rate

Process speed, powder feed rate

Scanner speed, stand-off distance, diameter ratio of the clad to powder stream for Gaussian mode distribution

Laser power, powder mass flux

[85] Shapes of manufactured structures, thermal loads

[86] Local temperature history, track profile, microstructure scale

[87] Spreading, cooling and solidification processes of droplets

[88] Thickness of the deposition layer, the depth of the molten pool, the penetration of the substrate or previous deposited layer

[89] Residual stresses, distortion

[90] Thermal modelling, residual stresses, thermal distortions

[91] Temperature, stress field

[92] Stresses, strains

[95] Bead geometry (layer thickness, dimensional precision)

[96] Microstructure, mechanical properties

[93] Residual stresses

[97] Microstructure, hardness, residual stresses

[94] Residual stress history, microstructure

[98] Total spread of droplet, solidification front speed, interlamellar spacing

[99] Microstructure, hardness

[100] Powder-to-solid transition

[101] Grain size, grain growth speed,

[115] Thermal history

[102] Spreading and shape of the droplet after impact

[103] Splashing of droplets

[104] Fingering and splashing of the droplet

[105] Desired shape after impact

[106] Microstructure, temperature field

Substrate velocity

Scanning speed, powder feeding rate, input electric current

High speed machining post-process

Temperature history

Deposition pattern

Heat input, layer thickness

Welding speed, wire feed rate, arc voltage

Pre-heating of substrate, scanning speed, idle time

Melt pool geometry, metal powder flow rate, laser power, scanning speed, scanning direction, and deposition layer thickness

Deposition parameters

Phase change

Droplet size, speed, superheat

Substrate size, idle time

Temperature, porosity-dependent conduction

Temperature, deposition over time

Laser-scan velocities

Substrate roughness and temperature, speed of droplet

Impact velocity, temperature

Droplet velocity, liquid type, temperature of surface, surface roughness, contact angle

Initial droplet shape

Number of layers, layer height, wire feed rate, travel speed, heat input 
Table7. (continued).

\begin{tabular}{|c|c|c|}
\hline $\begin{array}{l}\text { Reference } \\
\text { number }\end{array}$ & $\mathrm{KPI}$ & Process/Part parameter (Variable) \\
\hline$[107]$ & $\begin{array}{l}\text { Droplet spreading, final deposit shapes } \\
\text { times needed for initialization and } \\
\text { completion of freezing }\end{array}$ & $\begin{array}{l}\text { Initial droplet temperature, impact velocity, thermal } \\
\text { contact resistance and initial substrate temperature }\end{array}$ \\
\hline$[108]$ & $\begin{array}{l}\text { Fluid dynamics, Heat transfer related and } \\
\text { phase-change of droplet }\end{array}$ & \\
\hline$[110]$ & Solder bump characteristics, shape & Solder solidification \\
\hline [111] & Spreading and evaporation & Droplet material \\
\hline$[112]$ & $\begin{array}{l}\text { Droplet deformation and solidification, } \\
\text { Heat transfer related in the substrate, } \\
\text { maximum spread diameter }\end{array}$ & \\
\hline$[116]$ & $\begin{array}{l}\text { Heat transfer related, phase changes, and } \\
\text { fluid flow in the molten pool }\end{array}$ & \\
\hline$[117]$ & $\begin{array}{l}\text { Thermal modelling, calibration of input } \\
\text { parameters utilizing IR imaging }\end{array}$ & \\
\hline [118] & Thermal history, residual stresses & Induction heating patterns \\
\hline
\end{tabular}

Table 8. Classification of the of the modelling studies on the BJ AM process.

\begin{tabular}{lll}
\hline $\begin{array}{l}\text { Reference } \\
\text { number }\end{array}$ & KPI & Process/Part parameter (Variable) \\
\hline$[119]$ & Shrinkage rate, surface roughness & $\begin{array}{l}\text { Layer thickness, Printing saturation, Heater power } \\
\text { ratio, drying time } \\
\text { Type of binder, powder-bed characteristics }\end{array}$ \\
{$[120]$} & $\begin{array}{l}\text { Surface finish, dimensional accuracy, resolution, } \\
\text { surface roughness, pore size }\end{array}$ & Drag force, droplet deflection \\
{$[121]$} & $\begin{array}{l}\text { Topology, droplet kinematics } \\
{[122]}\end{array}$ & $\begin{array}{l}\text { Energy consumption } \\
{[123]}\end{array}$ \\
\hline
\end{tabular}

optimizing the process mechanics can lead to the improvement of such issues. In Table 8, the modelled KPIs and the process parameters used in each study can be seen. In [119], empirical models of shrinkage rate, surface roughness are presented, whereas [120] and [121] deal with topology issues analytically and numerically respectively. In [122] an analytical energy consumption model has been developed, while a semi-analytical approach is presented in [123]. Studies using a numerical approach [113,121] model droplet kinematics and flow phenomena.

\subsection{Material extrusion}

The commercial name of material extrusion is fused deposition modelling (FDM). Some of the major issues that deteriorate the quality of parts are analyzed. The cooling process profile determines the part distortions and as a result, material warping can be the effect of nonlinear cooling. Furthermore, the creation of porous parts is possible and it is also determined by the cooling profile. More specifically, the temperature differences among the building platform, chamber and the different layers of the part, play a major role. In addition, the temperature of the extruder and that of the layer on which the filament is placed, determines the success of the bonding between them and as a result, the mechanical properties of the final part [11]. Another important issue is the fact that the creation of the parts' material properties via material extrusion is anisotropic. This is due to the crisscrossing manner used by the material extruder in order to deposit the filament [137]. Thermal modelling issues concerning the material properties and dimensional accuracy, as well as the improvement of other KPIs, namely, building speed and surface roughness, are the main areas that modelling 
Table 9. Classification of the of the modelling studies on the ME AM process.

\begin{tabular}{|c|c|c|}
\hline $\begin{array}{l}\text { Reference } \\
\text { number }\end{array}$ & KPI & Process/Part parameter (Variable) \\
\hline [137] & Tensile strength & Air gap, raster orientation, other parameters \\
\hline [124] & Surface roughness & $\begin{array}{l}\text { Surface angle, layer thickness, cross-sectional shape of the } \\
\text { filament, overlap interval }\end{array}$ \\
\hline [125] & Build time, surface roughness & Part deposition orientation, surface roughness \\
\hline [126] & Surface roughness & Layer thickness, build orientation \\
\hline$[127]$ & Surface roughness & Layer thickness \\
\hline [128] & Surface roughness & $\begin{array}{l}\text { Layer thickness, orientation, raster angle, raster width, air } \\
\text { gap }\end{array}$ \\
\hline [129] & Dimensional deviations & Layer thickness, deposition angle \\
\hline [130] & Residual stresses, part distortions & Scan speed, layer thickness, tool path width \\
\hline [131] & Dimensional accuracy & $\begin{array}{l}\text { Layer thickness, part orientation, raster angle, air gap and } \\
\text { raster width }\end{array}$ \\
\hline [132] & Mechanical properties & Building direction, number of contours \\
\hline$[133]$ & Bonding quality among polymer filaments & Heating/cooling rates \\
\hline [134] & Mechanical properties & Structural parameters \\
\hline [135] & Mechanical and thermal phenomena & Tool path patterns \\
\hline [136] & Material flow through liquefier & Temperature, velocity, drop of pressure \\
\hline [138] & Compressive stress & $\begin{array}{l}\text { Layer thickness, part build orientation, raster angle, raster } \\
\text { width and air gap }\end{array}$ \\
\hline [139] & Tensile, flexural and Impact strength & $\begin{array}{l}\text { Layer thickness, orientation, raster angle, raster width, air } \\
\text { gap }\end{array}$ \\
\hline [140] & Sliding wear & $\begin{array}{l}\text { Layer thickness, part build orientation, raster angle, raster } \\
\text { width and air gap }\end{array}$ \\
\hline [141] & Elasticity, flexibility & Air gap, raster angle, raster width, layer thickness \\
\hline [142] & Build time & Acceleration of scan head, part complexity, path planning \\
\hline
\end{tabular}

studies on ME concentrate. In Table 9, a summarization of the process parameters and KPIs of the different modelling approaches can be seen. More specifically, surface roughness modelling is more extensive in ME, with the analytical approach of [124], the numerical of [125] and the empirical ones of [126-128]. Topology and dimensional accuracy issues have been modelled in [129,132-134] using analytical methods, whereas in $[125,135,136]$ numerical ones have been used and in [137-141] the empirical approach has been followed. Also, the dimensional deviations, caused by changes made in layer thickness and deposition angle, are analytically modelled in [129].

Moreover, in [130], a FEA model is used for the evaluation of a part's distortions, using a parametric study, for the evaluation of the deposition parameters effects on residual stresses and part distortions. FEA has been used in [135] for the simulation of the mechanical, thermal phenomena, the tool-path effects, the residual stresses and the part's distortions. Also, in [136], 2D and 3D numerical analysis of melt flow behaviour of a representative ABS-iron composite, through the liquefier head, has been carried out, whereas in [141], ANOVA has been employed to investigate into the impact of various process parameters on elastic performance. Modelling of build time takes place in [142] in which both an analytical and empirical, whereas, in [125] a real coded genetic algorithm is used in order to obtain the optimum solution, concerning the part's deposition orientation, the simultaneous enhancement of its surface finish and the reduction in build time. Finally, in the studies of [147] and [155] heat related KPIs are also modelled utilizing numerical approaches.

\subsection{Material jetting}

The technical problems of the MJ process are various. Some of the most important factors are the droplet velocity and size, which play a major role in the deposition characteristics. In addition, the satellite droplets, that break off from the main droplet, during the flight and result in not welldefined boundaries [104], along with the droplet splashing on impact, leading to the formation of a "crown" [105], have to be tackled with, in order for the quality of parts created by MJ to be increased. Consequently, fluid dynamics, in which temperature is also taken into account, has to be used so as to address the most important issues faced by the MJ process group. In Table 10, a summarization of the process parameters and KPIs of the different modelling approaches can be seen. 
Table 10. Classification of the of the modelling studies on the MJ AM process.

\begin{tabular}{|c|c|c|}
\hline $\begin{array}{l}\text { Reference } \\
\text { number }\end{array}$ & KPI & Process/Part parameter (Variable) \\
\hline [17-19] & Etching, deposition, lithography mechanics & Surface type, material, shape \\
\hline [143] & Deformation behavior of droplets & Impact angle \\
\hline [144] & Stiffness & $\begin{array}{l}\text { Spatial orientation of reinforcement in randomly } \\
\text { oriented multi material }\end{array}$ \\
\hline$[145]$ & Pressure, axial velocity histories & \\
\hline [104] & Fingering and splashing of the droplet & Droplet velocity \\
\hline$[105]$ & Desired shape after impact & Initial droplet shape \\
\hline [106] & Microstructure, temperature field & $\begin{array}{l}\text { Number of layers, layer height, wire feed rate, } \\
\text { travel speed, heat input }\end{array}$ \\
\hline [111] & Spreading and evaporation & Droplet material \\
\hline$[147]$ & Droplet volume, temperature, and pressure & Heating pulse conditions \\
\hline [148] & Pressure rise, ink injection length, droplet weight & Electric pulse shape and voltage \\
\hline [149] & $\begin{array}{l}\text { Vapor blanket height between the evaporating } \\
\text { droplet, substrate, formation of vapor bubbles }\end{array}$ & Temperature \\
\hline$[150]$ & $\begin{array}{l}\text { Drop formation, ejection, spread and flow of } \\
\text { ceramic inks in micro-channels }\end{array}$ & $\begin{array}{l}\text { Solid loading concentrations of alumina/zirconia } \\
\text { powder in ceramic inks }\end{array}$ \\
\hline [151] & Pressure propagation in the bubble & \\
\hline$[152]$ & $\begin{array}{l}\text { Magnitude of the circular thin film of the incoming } \\
\text { droplets }\end{array}$ & Impact velocity \\
\hline$[153]$ & $\begin{array}{l}\text { Droplet morphology, break-up time, flying distance, } \\
\text { droplet volume }\end{array}$ & \\
\hline$[154]$ & Droplet volume, droplet velocity & $\begin{array}{l}\text { Driving time, driving volume in the pressure } \\
\text { chamber, volume factor }\end{array}$ \\
\hline$[155]$ & Droplet fluid dynamics and heat transfer related & \\
\hline
\end{tabular}

Table 11. Classification of the of the modelling studies on the LOM AM process.

\begin{tabular}{|c|c|c|}
\hline $\begin{array}{l}\text { Reference } \\
\text { number }\end{array}$ & KPI & Process parameter (Variable) \\
\hline [156] & Surface roughness & Layer thickness, orientation angle \\
\hline$[157]$ & Surface roughness & Layer thickness, roller temperature, roller speed, platform retract \\
\hline$[158]$ & Surface roughness & $\begin{array}{l}\text { Layer thickness, heated roller temperature, heated roller speed, platform } \\
\text { retract }\end{array}$ \\
\hline [159] & Organic content & Effective diffusivity, diffusion path length, distance from core \\
\hline [160] & Thermochemical modelling & Roller temperature, velocity, indentation \\
\hline [161] & Tensile strength & $\begin{array}{l}\text { Layer thickness, heater temperature, platform retract, heater speed, laser } \\
\text { speed, feeder speed, platform speed }\end{array}$ \\
\hline [162] & Build time & \\
\hline [163] & Build time & Cross-hatching of extraneous material \\
\hline [164] & Temperature profile & $\begin{array}{l}\text { Roller temperature, roller speed, chamber air temperature, base plate } \\
\text { temperature, and laser cutting time }\end{array}$ \\
\hline [165] & Thermal modelling & $\begin{array}{l}\text { Roller temperature, roller speed, chamber air temperature, base plate } \\
\text { temperature, and laser cutting time }\end{array}$ \\
\hline
\end{tabular}

Most of the studies that refer to the MJ process group focus on the droplet kinematics and the flow phenomena. Namely, [104-106,111,121,143,146-153] in which numerical approaches have been used, whereas in [154] empirical and in [145] analytical ones have been used. In [17$19,121,143]$ issues of topology have been addressed by means of the numerical methods and in [144] the effects of various process parameters on the mechanical properties of 
Table 12. Classification of the of the modelling studies on the UC AM process.

\begin{tabular}{|c|c|c|}
\hline $\begin{array}{l}\text { Reference } \\
\text { number }\end{array}$ & KPI & Process parameter (Variable) \\
\hline [167] & Linear weld density & $\begin{array}{l}\text { Oscillation amplitude, welding speed, normal force, } \\
\text { substrate temperature }\end{array}$ \\
\hline [168] & $\begin{array}{l}\text { Solid state diffusion and bonding, } \\
\text { microstructural deformation mechanisms }\end{array}$ & Surface effects (friction work, temperature) \\
\hline [169] & Linear weld density & $\begin{array}{l}\text { Energy input to the workpiece within a single cycle of } \\
\text { ultrasonic vibration, total energy input to the workpiece }\end{array}$ \\
\hline$[170]$ & Yield stress & Thermal, acoustic softening \\
\hline$[171]$ & $\begin{array}{l}\text { Amplitude of contact friction stress and } \\
\text { displacement }\end{array}$ & Vibration condition, substrate height \\
\hline [172] & Dislocations and bonding fragmentation & \\
\hline [173] & Friction behaviour at the interfaces & $\begin{array}{l}\text { Velocity of sonotrode, displacement amplitude of } \\
\text { ultrasonic vibration, applied loads }\end{array}$ \\
\hline [174] & Residual stress and distortion & Support structure \\
\hline$[175]$ & Weld strength & Contact pressure, amplitude, welding time \\
\hline [176] & $\begin{array}{l}\text { Ultimate shear strength, ultimate transverse } \\
\text { tensile strength }\end{array}$ & Tack force, weld force, oscillation amplitude, weld rate \\
\hline
\end{tabular}

parts have been empirically simulated. Finally, heat transfer related issues have been modelled in [147] and [155] using numerical approaches.

\subsection{Sheet lamination}

The different methods used for the bonding of the new sheet on top of the other ones are (a) gluing or adhesive bonding, (b) thermal bonding, (c) clamping, and (d) ultrasonic AM. The adhesive bonding and ultrasonic AM will be presented in the following sections. However, the thermal bonding (sheet metal lamination process) and clamping sheet lamination will not be presented in this study, given that the first has gained little commercial attention [11] and the modelling of the second is beyond the scope of this study.

\subsubsection{Gluing or adhesive bonding}

The commercial name of this process group is laminated object manufacturing (LOM). The main problems faced by LOM, to some extent, are similar to those of ultrasonic consolidation (UC). In Table 11, the aforementioned studies, along with their process parameters have been summarized. More specifically, if the laser power induces more thermal energy than it is required, the efficiency of the bonding between layers is reduced. Moreover, phenomena of part distortions, due to non-uniform heating and cooling and also edge roughness are common [166]. In order to cope with such problems, most of the modelling studies on LOM are thermal simulations ([164] analytical and $[160,165]$ numerical). A surface roughness model has been developed in [156] through an analytical approach, whereas in [157] and [158] an empirical approach has been followed. In [159], an analytical microstructure model has been developed. Numerical modelling of the mechanical properties has been conducted in [160] and an empirical one in [161]. Finally, two build time models, one analytical [162] and one numerical [163] have been included.

\subsubsection{Ultrasonic AM}

In ultrasonic additive manufacturing or $\mathrm{UC}$, which is the most common commercial name of this process, the most common defects are voids created during the fusion of the different layers of sheets between them, leading to the deterioration of the mechanical properties. Those voids can be classified into three different categories: those that are created because (i) of the surface roughness of two consecutive layers, (ii) of damages due to excessive energy input, (iii) of defects between adjacent layers [167]. Moreover, the mechanical properties tend to be anisotropic because of the difference in the mechanical properties between the interior of the metal foils and the areas where bonding between the different foils takes place. This anisotropy is greater in the $z$ than it is in the $x, y$ directions. Finally, the local microstructure also plays a major role in the final part's mechanical properties, considering that some parts of the foils undergo plastic deformation during the process. As a result, the modelling works on UC aim to determine the process parameters that will ensure optimized mechanical properties and a microstructure, with minimization of the void defects and maximization of the linear welding density (the percentage of interface which is bonded, divided by the total length of the interface between two ultrasonically consolidated foils). In Table 12 , there is a summary of the aforementioned studies.

More specifically, modelling of the mechanical properties has been carried out in $[168,169]$ using analytical approaches, whereas in $[170,171-175]$ numerical methods have been utilized and in $[167,176]$ empirical ones. 

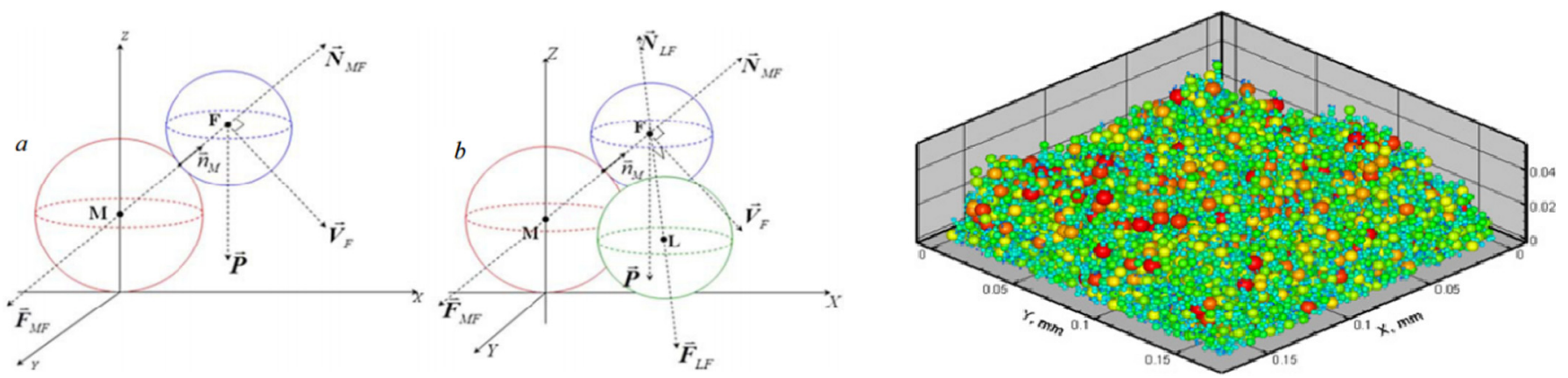

Fig. 2. Left: Free body diagrams of different types of motions of the powder particles [48], Right: Results of the model of [48].

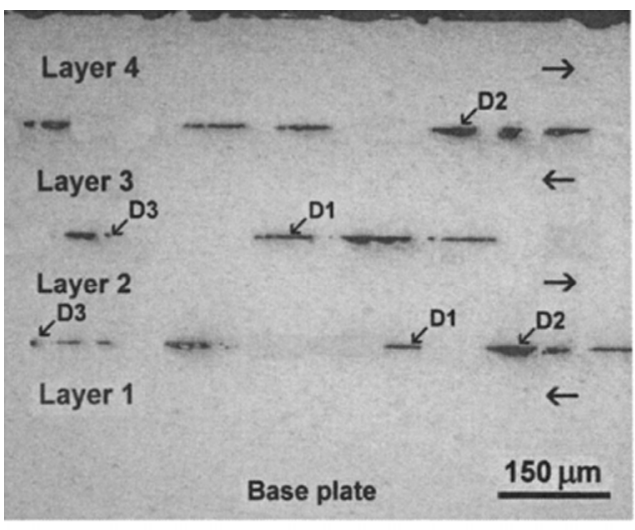

(a)

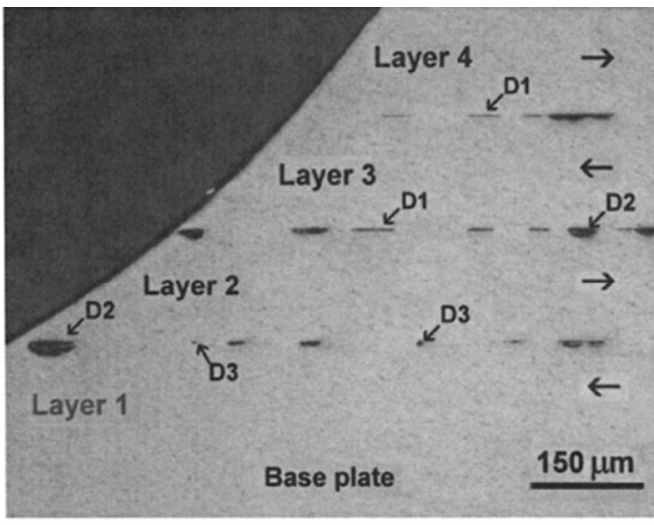

(b)

Fig. 3. Microstructure of the parts of the experiments conducted in [167].

\section{Indicative studies for each KPI group}

In this section, a KPI-centered perspective is followed. More specifically, three or more indicative modelling approaches, namely analytical, numerical and empirical will be presented for each KPI group, in a more detailed way.

\subsection{Mechanical properties and microstructure}

In [48], Kovaleva et al. have analytically modelled the internal structure of a loose powder layer of the SLM process. Using the vector equations of motion, they have created a system of five equations, whose solution has provided the positions of the powder particles. On the left of Figure 2, the free body diagrams can be seen and on the right, a sample solution, which has resulted from an analytical solution, is depicted.

Kumar et al., in [98], have created a numerical model that takes into account both the fluid flow and the heat transfer phenomena happening in DMD. The spead of the droplet, the solidification speed and the interlamellar spacing have been simulated. The solidification front velocities, which were calculated by the model, have been imported in the Jackson-Hunt relationship. In [167], Ram et al. adopt a design of experiments (DOE) approach in order to evaluate the effects of various process parameters on the microstructure and the laser weld density of the UC process. Some of the experimental results used for the creation of the empirical model, can be seen in Figure 3.

A more macroscopic approach to the modelling of a part's material properties, created with the use of ME is presented in [137]. More specifically, the DOE method has been followed in order for the importance of various process parameters of FDM to be determined. A macroscopic approach has been utilized and the parameters examined were raster orientation, air gap, bead width, color, and model temperature. The impact on the tensile and compressive strengths of the aforementioned parameters has been evaluated. It was found that the tensile strength was mostly affected by raster orientation and air gap. In Figure 4 , the tensile strength of specimens with different raster angles, with air gap, can be seen and are also compared with the tensile strength of injection molded parts.

All three modelling approaches are suitable for the modelling of this KPI group, however, analytical models tend to be complex and capable of dealing with very specific cases. However, if the set of assumptions are carefully selected keeping in mind the exact aim for which the simulation will be used, they are capable of fairly accurate and fast to run simulations. Such analyses can be used as a first approach for a problem, or even for process control, for which the combination with experiments and empirical equations can contribute to an increase of the accuracy of 


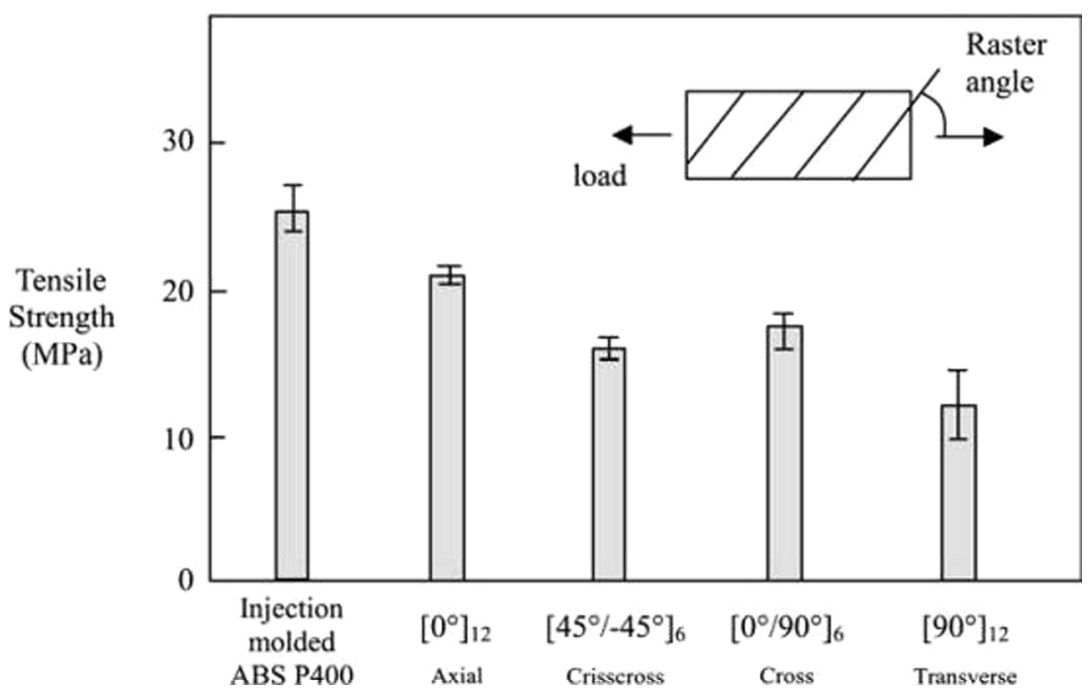

Fig. 4. Tensile strength specimens with various raster (-0.003 inch air gap) compared with injection moulded parts [137].

the methods. The numerical approach is capable of producing very accurate results for this KPI group, however, they require a longer developing and optimization and require long run times.

\subsection{Dimensional accuracy}

Thermal models have been created in order to model the part's cooling, which is responsible for the residual stresses and thermal distortions. Thermo-mechanical models have also been created in order to enable the prediction of thermal stresses and distortions, which may lead to the loss of quality due to the deterioration of the dimensional accuracy or even to a total component failure (unacceptable distortions or breakage). Indicative models using an analytical, numerical and experimental approach follow. An analytical approach was made by Lalas et al. [82] and Salonitis et al. [83] for the calculation of the geometrical characteristics of the produced part. More specifically, the surface tension theory has been applied and geometric relations have been used for the calculation of the following equations, which estimate the geometry of the parts, manufactured via DMD:

$$
\begin{gathered}
w=2 R \sin \theta, \\
d=R_{b}(1-\cos \phi), \\
h=R_{u}(1-\cos \omega) .
\end{gathered}
$$

In Figures 5 and 6 the symbolisms of the equations can be seen.

In [28], the finite difference and finite element approaches, in combination with analytical expressions of the thermal properties, have been used in order to model the temperature history in the SLS AM process. Its impact on the part's shape has also been taken into account. The boundary condition used is the prevention of heat loss from

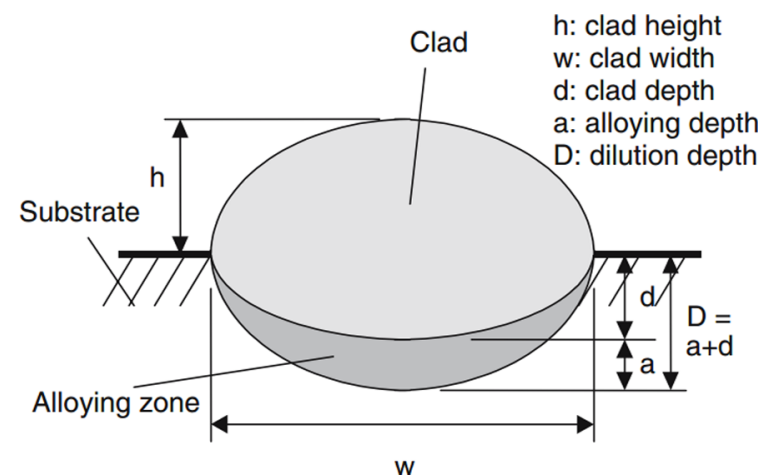

Fig. 5. Clad geometric characteristics [82].

the free surface boundary, while all the others were held at ambient temperature. The thermal conductivity and heat capacity were assumed to exhibit a linear variation in temperature. The variation in density in the $z$ axis has also been taken into account and calculated via a viscous sintering law, presented in the paper. The variation in thermal conductivity with density follows an experimentally created equation. This model has been utilized for the calculation of the change in dimensions, due to the thermal phenomena that take place during the manufacturing of the part.

In [131], the Taguchi method for the design of experiments was used for the study of the effect on the dimensional accuracy of the ME process of layer thickness parameters, part build orientation, raster angle, raster to raster gap (air gap) and raster width, having taken into account the build orientation.

The fact that this KPI group is directly connected with thermal phenomena, for most of the processes, render the numerical approach as the most suitable one. However, analytical simulations can be very useful for certain cases, like a fast first indication, and the empirical approach can be utilized for accurate results, but for specific cases. 

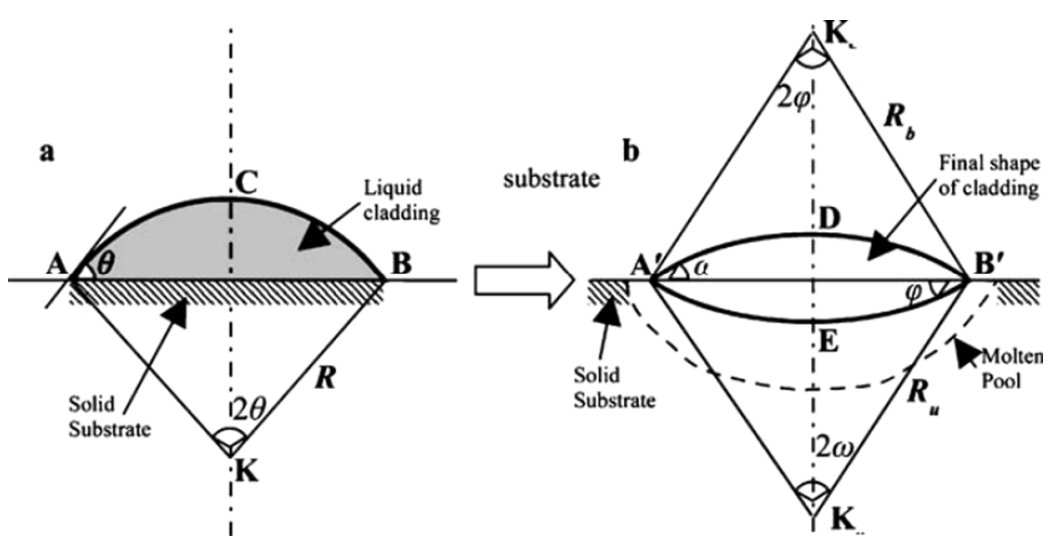

Fig. 6. Clad formation. a) First stage: liquid clad, solid substrate. b) Final stage: liquid clad and substrate.
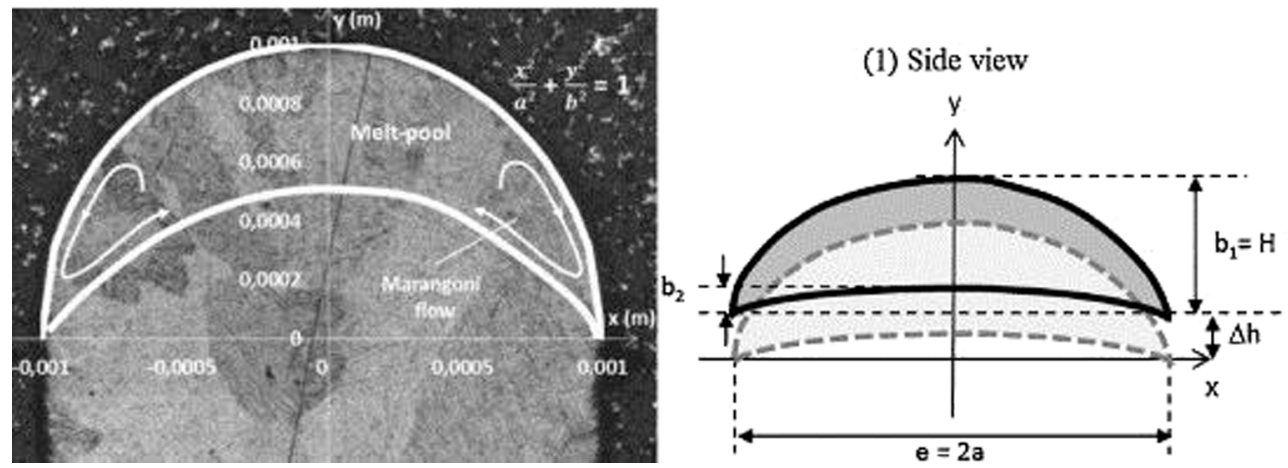

(2) Zoom on intersection zone

Fig. 7. Description and symbolism of the analytical model of Gharbi et al. [78].

\subsection{Surface roughness}

In the analytical model of Gharbi et al. [78] for DMD, each melt-pool is considered as the sum of two semi-ellipses $\frac{x^{2}}{a^{2}}+\frac{y^{2}}{b^{2}}=1$ (one for the upper part, and one for the lower part) on a $2 \mathrm{D}$ cross section. This model predicts the roughness, based on the analytical solution of the equation that follows. Details about the symbolisms can be found in Figure 7.

$$
w_{p}=\frac{e}{2}\left(1-\left(\sqrt{1-\left(\frac{\Delta h}{H_{1}\left(1 \pm\left(\frac{1}{n}\right)\right)}\right)^{2}}\right)\right) .
$$

In [56], Chunlei et al. have developed a 3D CFD model for the SLM process, to simulate the interaction between the laser beam and the powder layer, which takes into account the splashing of molten material and evaporation. As a result, features of dents/discontinuities have been calculated on the top surfaces due to the melt recirculation and splashing. This model is enabled to predict the roughness of a part's surface. In Figure 8, the results of a sample analysis using the developed model can be seen.

In [127], Anitha et al. have used the Taguchi techniques in order to analyze the effect of different process parameters on the surface roughness of components, produced by the ME process. Their goal is the minimiza- tion of surface roughness, whilst the process parameters used are: layer thickness, road width and speed of deposition. It was found that the most important factor was that of layer thickness.

In the processes that a melt pool is created (PBF, DED) and even more so in the powder jetting applications of DED, a CFD analysis, coupled with a thermal model is required in order to obtain accurate results of this KPI, since the phenomena that take place are coupled and are dynamic in space and time. However, with careful assumptions, analytical solutions are also possible. Finally, the direct way that roughness can be measured is in favor of empirical models, which utilize experimentation.

\subsection{Building speed}

In [29], the build time of the SLS AM process has been analytically modelled. The full time that is necessary for the part's creation is calculated by summing up the time required for each layer. The time required for the creation of one layer has been divided into the scan and set-up time (the second one can be obtained from the machine's manual). Using the following equation, the time it takes for the scanning of a layer is obtained by:

$$
T_{l}=\frac{L_{d}}{L_{v}},
$$



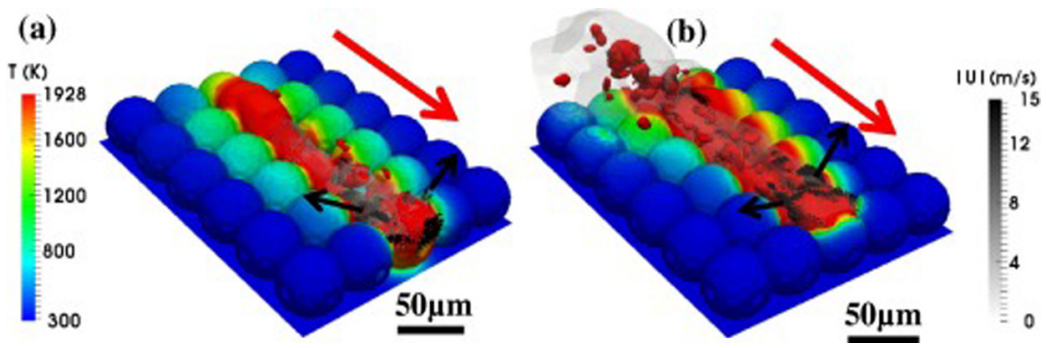

Fig. 8. Thermal fluid flow prediction of two different powder particles sizes of [56].

where $L_{d}$ is laser scan distance, $L_{v}$ is the laser scan velocitywhere $m$ is the total number of layers, the sum of the length of and $T_{l}$ is the scan time of a layer. The total scan distance within a layer, can be obtained from the hatch file. The velocity has been estimated by:

$$
v=\frac{P_{l}(1-R)}{\rho d_{b} l_{m}\left[C_{p}\left(T_{m}-T_{b}\right)+k L_{h}\right]},
$$

where $P_{l}$ is the laser power, $R$ is the reflectivity of the mirror, $\rho$ is the material density, $d_{b}$ is the laser beam diameter, $l_{m}$ is the machine layer thickness, $C_{p}$ is the specific heat, $T_{m}$ is the melting temperature, $T_{b}$ is the bed temperature, $k$ is the sinter factor and $L_{h}$ is the latent heat. The setup time refers to the required time for the laying of each new layer and every other machine function when it is not sintering:

$$
T_{s}=t_{w d}+t_{d}+t_{w r}+t_{h}
$$

where $t_{w d}$ is the time required for the work-bed to move down, $t_{d}$ is the material deposition time, $t_{w r}$ is the time required for the work-bed to rise up and $t_{h}$ is the time required for the material to be heated. Finally, the build time can be calculated by:

$$
\text { Build-time }=\sum_{i=1}^{N_{l}} T_{l i}+T_{s} N_{l}
$$

where, $N_{l}$ is the total number of layers.

In [163], an octree-based algorithm has been presented for the determination of the laser's path, for the LOM AM process's cross-hatching operation to be performed. The results of this numerical calculation have been utilized for the estimation of the build time of the process. More specifically, the total laser path, with the use of the variable-size cross hatching presented before is:

$$
\begin{aligned}
L_{T O T, V} & =\sum_{i=1}^{m}\left[\operatorname{len}\left(L_{V i}\right)+\operatorname{len}\left(L_{H i}\right)+\operatorname{len}\left(L_{A i}\right)\right. \\
& \left.+\operatorname{len}\left(L_{F i}\right)\right]
\end{aligned}
$$

while in the case of a fixed cross-hatching, equation (11) is used:

$$
L_{T O T, F}=\sum_{i=1}^{m}\left[\operatorname{len}\left(L_{F C V i}\right)+\operatorname{len}\left(L_{F C H i}\right)+\operatorname{len}\left(L_{A i}\right)\right]
$$
all the line segments of the $i$ layer in the $L_{X}$ list is $\operatorname{len}\left(L_{X i}\right)$, the $V$ and $H$ suffixes refer to vertical and horizontal lines respectively, in reference to the laser path, generated for the variable-size cross-hatching, $A$ refers to the lines in the actual profile, while $F$ to the filler lines. Finally, $F C V$ and $F C H$ are used in order to indicate the vertical and horizontal lines respectively, for the fixed-size cubes. The improvement in the build time can be estimated by the reduction in the path length when the proposed algorithm is used for the determination of the laser path. The use of the proposed numerical solution for the minimization of the tool path, leads to its reduction in the build speed, by reducing the tool path, which is analogous to the build speed. This reduction is analytically calculated, and as a result, this modelling approach is a hybrid one.

In [44], an empirical approach, via ANN, has been utilized for the creation of a model, capable of estimating the build time of the SLS AM process. More specifically, a multilayer perceptron architecture, using the Levenberg Marquardt algorithm, has been utilized. The most useful input parameters were identified through a series of correlation analyses and the parameters: z-height, part volume, and bounding-box volume have been selected.

The learning and generalization capabilities of an ANN, and not those of specific programming, mainly determine the accuracy of the results. Consequently, the training and learning algorithms that will be used are of crucial importance. Here, the following degree of similarity is used in order to determine the cases included in the training sample of the NN:

$$
\begin{aligned}
& D S=\frac{\sum_{i=1}^{n} W_{n} \operatorname{sim}\left[a_{n} ; b_{n}\right]}{\sum_{i=1}^{n} W_{n}}, \\
& \operatorname{sim}\left[a_{n} ; b_{n}\right]=1-\frac{\left|a_{n}-b_{n}\right|}{a_{n}+b_{n}},
\end{aligned}
$$

where $a_{n}$ is the value of attribute $n$ in case $a, b_{n}$ is the value of attribute $n$ in case $b$, sim is the degree of similarity between the two cases $a$ and $b$, regarding attribute $n$ and $W_{n}$ is a weighting factor for the feature $n$. In the following picture, the errors of the model, presented in [44], are compared with those of [45] and [177], in which empirical and analytical build time modelling approaches are also presented (Fig. 9). 


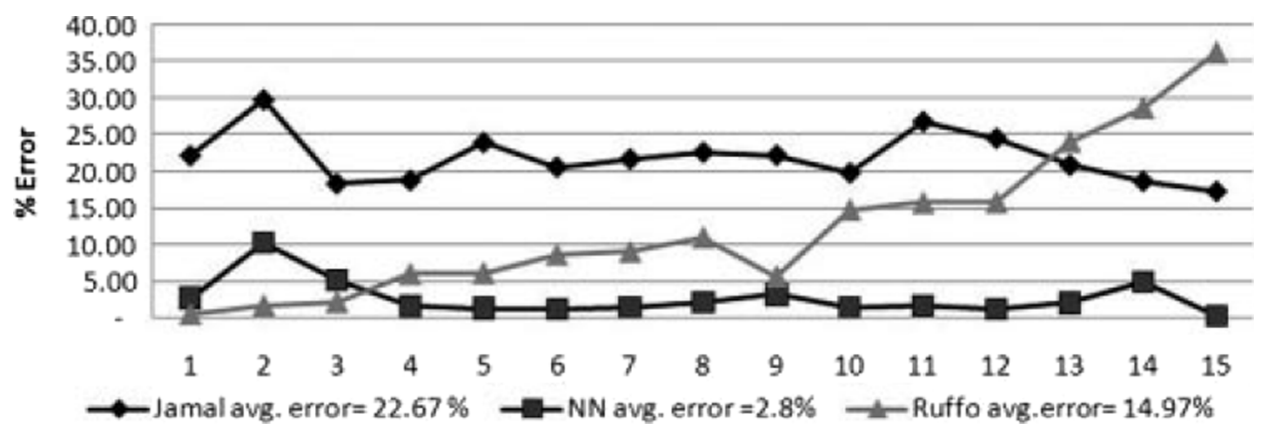

Fig. 9. Error estimation percentages between the models developed in [44,177] and [45] respectively.

The analytical approach is the most appropriate for the modelling of this KPI, followed by empirical modelling.

\subsection{Energy consumption}

Even though the aforementioned issues are of greater importance for the time being, the optimization of energy consumption of the AM processes is closely related to cost and as a result, it should also be analyzed. In [47], an analytical model, presented in [46], is used for the calculation of the energy consumption in the SLS process. According to [46], the laser energy input, required to sinter the powder of one layer is:

$$
e=a_{R} I_{\mathrm{avg}}\left(\frac{2 B}{V_{s}}\right),
$$

where $e$ is the energy per unit area, $a_{R}$ is the absorptivity of the powder, $I_{\text {avg }}$ is the average intensity of the laser beam, $B$ is the laser beam radius as measured on the powder bed and $V_{s}$ is the scanning speed of the laser. The total energy can be calculated by summing the energy required for the creation of each layer:

$$
E_{L}=\sum_{i=1}^{n_{s}} e A_{i}
$$

where $n_{s}$ is the number of slices and $A_{i}$ is the surface area of the $i$-th slice. In this equation, the laser intensity is substituted in order to be related to the laser power and the sum of the surfaces of the layers, while $\sum e A_{i}$ is termed as the total area of sintering (TAS). A numerical method for the calculation of a part's TAS is then proposed. As a result, the approach of [46] to the calculation of the SLS AM process's energy consumption is a hybrid analyticalnumerical one.

In [123], an analytical equation for the energy consumption has been used:

$$
E=\sum_{i=1}^{n_{p}} \int_{t_{i . S}}^{t_{i . E}} P_{i}(t) d t
$$

where $i$ is the number of sub-processes, $t_{i . S}$ is the start and $t_{i \text {. }}$ ${ }_{E}$ is the end time of each sub-process and $P_{i}(t)$ is the electrical power required for the sub-process $i$. More specifically, the different sub-processes defined are: (i) the drying of a printed layer, (ii) the printing of a new layer and (iii) the spreading of a new layer. In the following equation, $t_{\mathrm{p}}$, which is the operation time of printing is calculated:

$$
t_{p}=2 n \frac{Y_{\max }}{V_{\text {printhead }}}+t_{0},
$$

where the $Y$ variables indicate the movement of the printer head along the $y$-axis, during the binder deposition, $n$ is the number of repetitions and $t_{0}$ is a preparation time. Utilizing experimental results and using a linear regression, the previous analytical expression is modified and the following is calculated:

$$
t_{p}=0.09( \pm 0.004) Y_{\max }+23.767( \pm 2.4334) .
$$

The time required for the printing of a new layer is analytically calculated, by having utilized experimental data for the results' calibration and higher accuracy. The time needed for the spreading of a new layer is calculated by:

$$
\begin{aligned}
t_{s} & =\frac{X_{\text {left }}+X_{\text {right }}+X_{l \max }-X_{\text {min }}}{V_{s}} \\
+ & \frac{120-\left(X_{\text {left }}+X_{\text {right }}+X_{l \max }-X_{\text {min }}\right)}{V_{\text {rs }}}
\end{aligned}
$$

where $V_{s}$ is the spread speed, $V_{r s}$ is the rapid transverse speed and $X_{\text {left }}, X_{\text {right }}, X_{\text {lmax }}, X_{\min }$ are geometry parameters of the layer. The power required for each sub-process is experimentally measured and a mean value is calculated. As a result, the approach of [123], for the calculation of the SLS AM process's energy consumption is a hybrid analytical-empirical one.

For this KPI, which is directly connected to the build time, the analytical approach is, together with the empirical one, are ideal for its simulation.

\subsection{Droplet shape}

In [102], an analytical approach is used for the modelling on the shape of droplets that collide with the substrate and the effect of speed of the droplets, of the temperature and roughness of the substrate is taken into account. More specifically, assuming a loss of kinetic energy due to the freezing of the droplet on impact, starting from the energy balance equation the authors substitute the analytical 


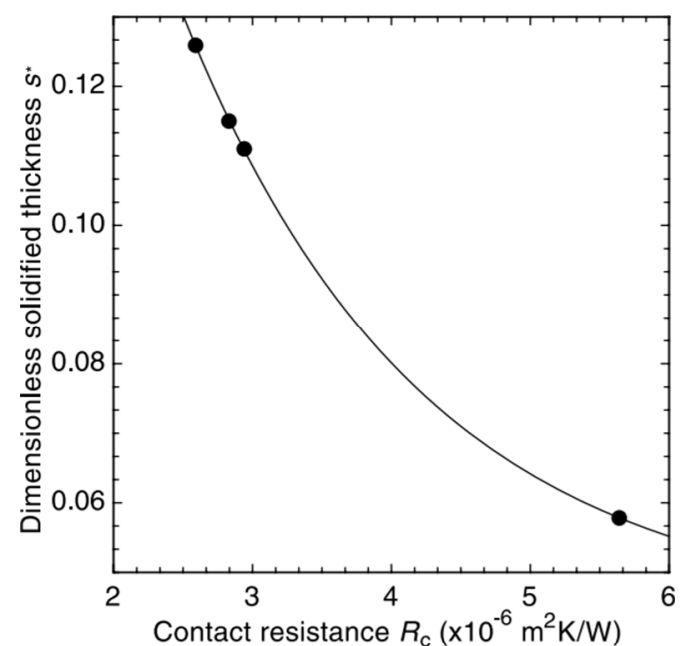

Fig. 10. Dimensionless solid layer thickness as a function of contact resistance [102].

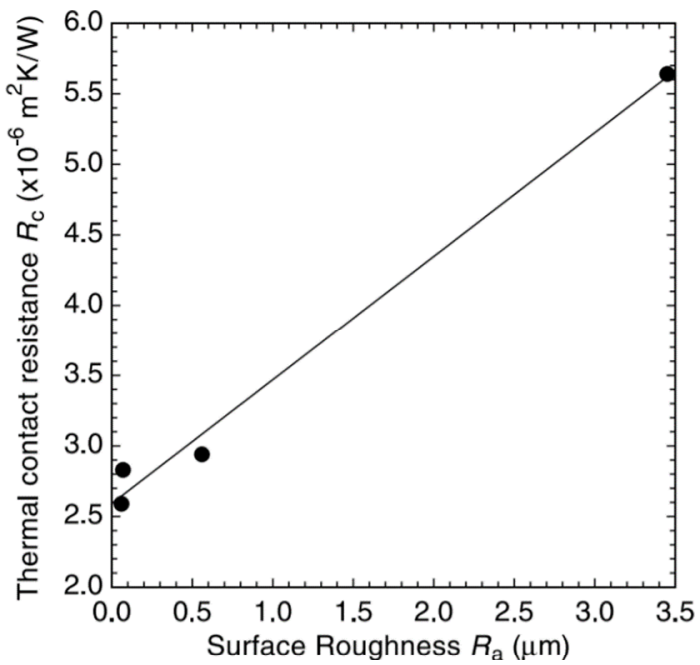

Fig. 11. Thermal contact resistance as a function of surface roughness [102].

expressions of the kinetic and surface energy of the droplet, measuring the contact angle from the experimental photographs and using an analytical expression for viscosity, the following expression for the maximum spread factor is obtained:

$$
\xi_{\max }=W e+1238 W e s^{*}+3(1-\cos \theta)+4 W e \operatorname{Re},
$$

where $W e$ is the Weber number, $R e$ is the Reynolds number and $s^{*}$ is the dimensionless solidified thickness. In Figure 10 the dimensionless solid layer thickness as a function of contact resistance is depicted, whereas Figure 11 the thermal contact resistance as a function of surface roughness, as calculated by the model of [102], can be seen.

Another analytical work is that of [103], in which transition temperature at which splashing disappears is calculated:

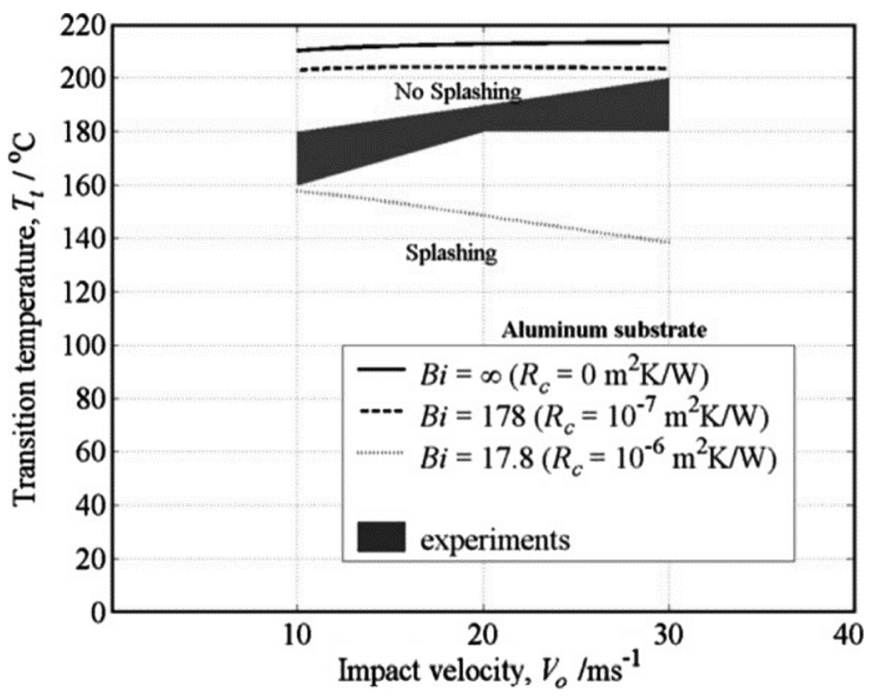

Fig. 12. Transition temperature as a function of impact velocity. Aluminum substrate with impact velocity of $V_{0}, R_{c}$ contact resistance at the droplet-substrate interface.

$$
T_{t}=T_{m}-\frac{S t e_{c} H_{f, d}}{c_{d}},
$$

where $S t e_{c}$ is critical expression for the Stefan number which is also calculated in [103], $H_{f, d}$ is the latent heat of fusion and $c_{d}$ is the specific heat. In Figure 12 the graph of transition temperature versus impact velocity can be seen.

A numerical approach on the droplet kinematics is presented in [104]. More specifically, the equations of the conservation of mass and momentum, which govern the flow within the liquid phase following impact have been discretized in a typical control volume formulation and solved numerically, using as boundary conditions the surface tension-induced pressure jump at the droplet surface, a zero tangential stress condition at the surface and the dynamic contact angle at the contact line of the solid, liquid, and gas phases. The explicit solution scheme has been used for convective, viscous, and surface tension effects, whereas pressure has been implicitly solved. Also, the deformation of the free surface is tracked using a piecewise linear volume tracking algorithm. An important characteristic of this study is the use of the continuum surface force model for the surface tension. Finally, the approach for the initiation of perturbation that has been followed is that the disturbance is not imposed on the moment of impact, but later, when the diameter of the droplet is just less than its initial diameter and a sufficient length has been acquired, so as to adequately resolve the perturbation that is imposed. This approach is practical and yields realistic results as can be seen in Figure 13.

In [154], the effects of driving time, volume in the pressure chamber, nozzle plate thickness and volume factor (process parameters) on the droplet volume and droplet velocity (KPIs) have been empirically modelled. In this study, the droplet size characteristics before their impact are modelled, which are determined by a drop-on-demand piezoelectric droplet generator. 


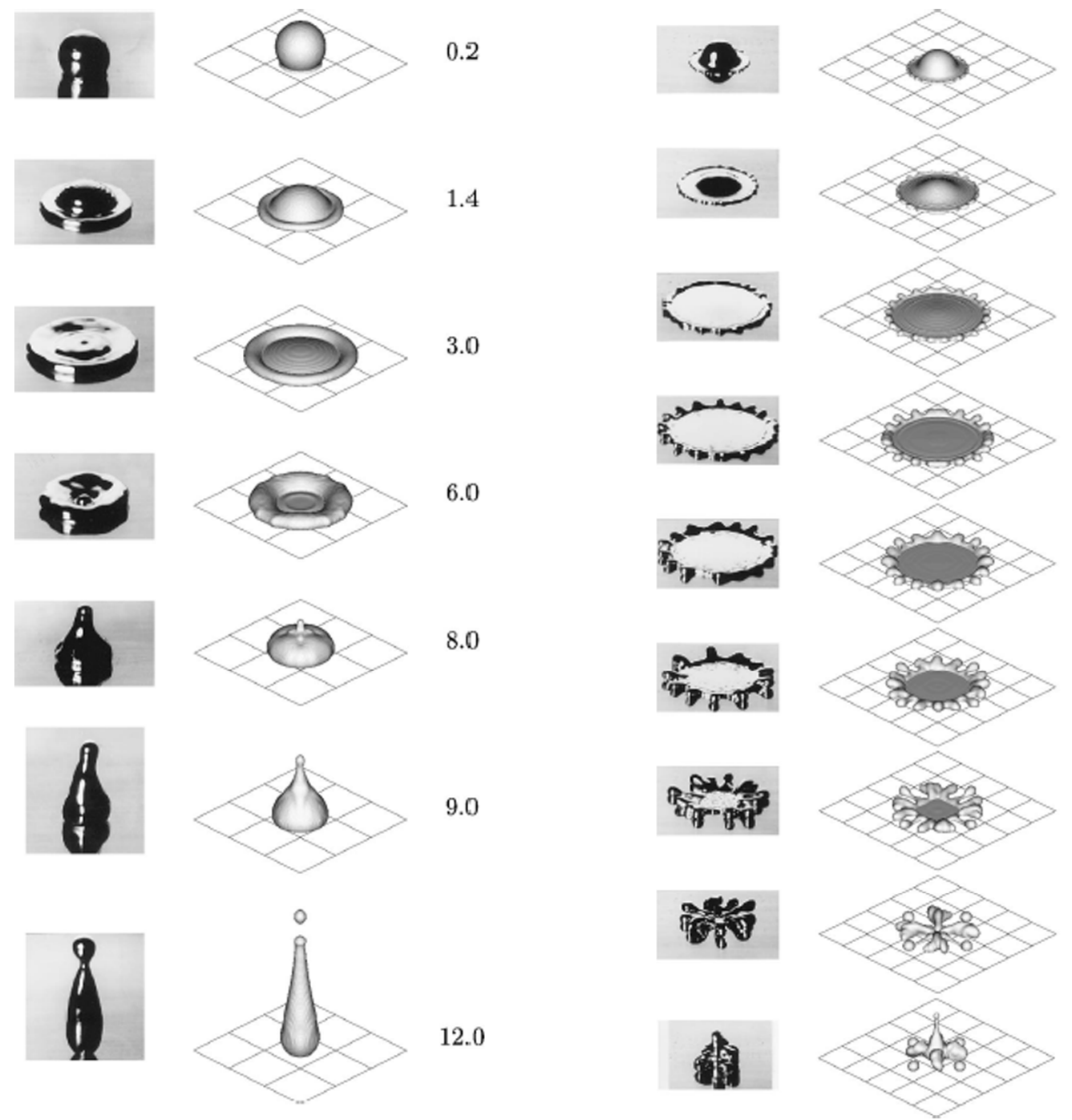

0.5

Fig. 13. Photographs and simulation results of the numerical model of the study [104]. Numbers at the right indicate milliseconds following impact.

From the above studies it can be concluded that for this KPI group all of the different approaches (analytical, numerical, empirical) should be utilized in the applications that each one is more suitable, so as to produce different results and to be capable to utilize all three complementary to each another.

\subsection{Heat transfer related KPIs/phenomena}

An indicative analytical approach is that of [114], in which the calculation of laser attenuation and powder temperatures at every point below a nozzle of a DED system (Fig. 14) is presented. The beam intensity is calculated at any position and it is utilized for the calculation of the temperature of the powder (Fig.15). The space below the nozzle is divided in two: that which is above the powder attenuation plane and that which is beyond; a different analysis is performed for each case. In the first part of the space, above the attenuation plane, the powder particles are divided between those that fall within the laser beam and those which fall outside. In the space beyond the attenuation plane, the powder particles are divided in three categories: those that are continuously under the laser beam, those that were in the beam at the consolidation plane but are beyond when in their final position and in those that undertook no further heating after the consolidation plane. For those five categories a different analytical equation for their temperature is provided.

In [118], a thermal analysis is presented, as part of the simulation of the Weld-based AM process. More specifically, the heat transfer equation is solved in workpiece taking into account both arc and induction heat input:

$$
\rho C_{p} \frac{\partial T}{\partial t}-\nabla(\lambda \nabla T)=Q_{a r c}+Q_{j h}
$$

where $\rho C_{p}$ is the volumetric specific heat, $\lambda$ is the thermal conductivity, $Q_{\text {arc }}$ is the arc heat term, and $Q_{j h}$ is the average induction heat rate over an electromagnetic period. A combined radiation-convection heat transfer coefficient is used as a boundary condition for the surfaces 


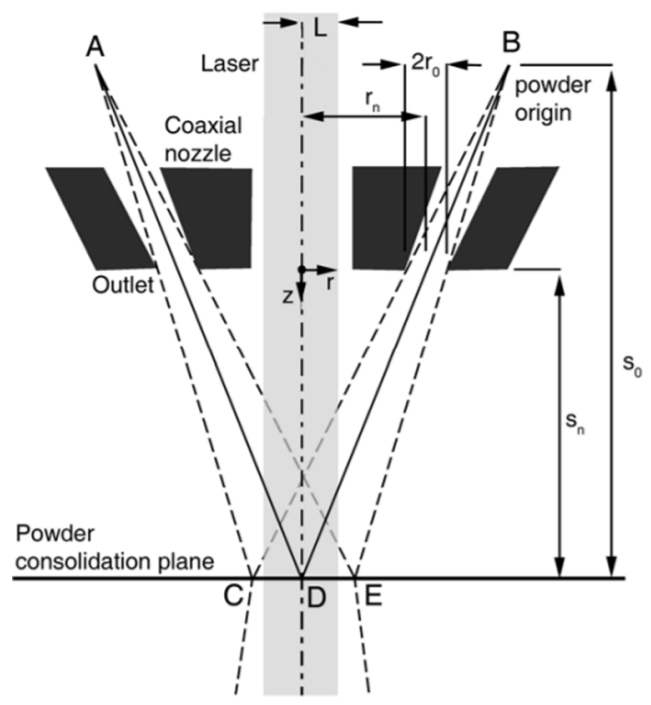

Fig. 14. Schematic diagram of the powder stream from a coaxial laser deposition nozzle, in which the powder consolidation plane is visisble [114].

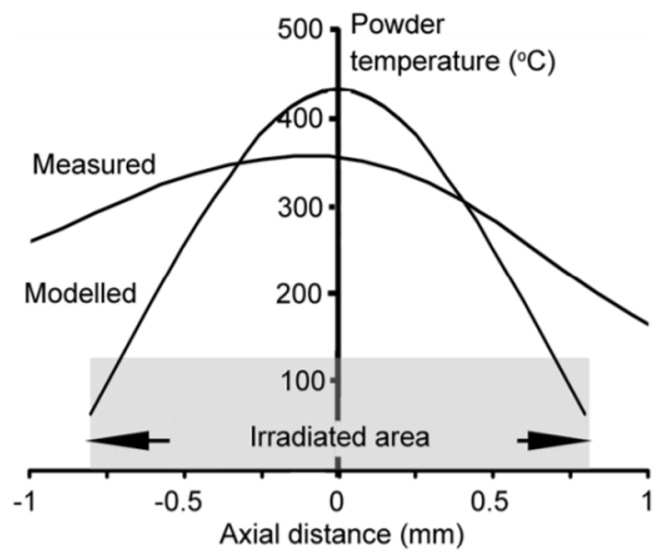

Fig. 15. Validation of the analytical model presented in [114].

of the workpiece. A FE discretization is utilized, the latent heat of phase transformation is taken into account by increasing the specific heat and the material properties are temperature dependent. Also, the increased convection of the melt pool due to fluid flow is simulated, by increasing the thermal conductivities by 10 times. Also, through a coupled electromagnetic analysis, which takes place only at a specific time so as to decrease computational costs and times, the induction heating is also taken into account in the thermal analysis, as pre-heating or post-heating. Consequently, the concept of this approach is the creation of a simulation of a relatively short duration of the actual process time of a complex AM process, for which both thermal and electromagnetic analysis is required; a smart coupling is used for decreasing the computational time, which still is in the scale that would not permit a simulation close to the real time of the process. In Figure 16, temperature plots of a two layer analysis that has been performed in [118] are depicted.
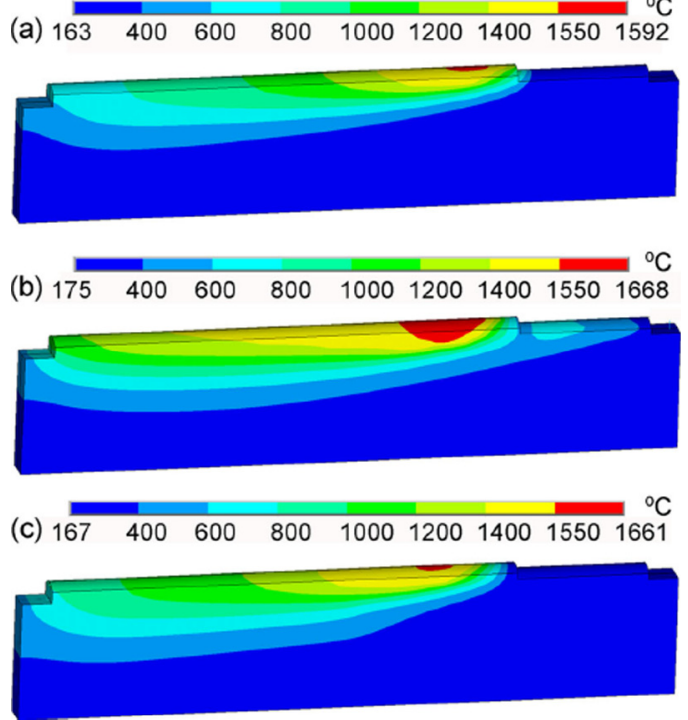

Fig. 16. Temperature filed during a two layer deposition simulation (a) no induction heating, (b) induction pre-heating, (C) induction post heating [118].

A different numerical approach of a thermal simulation is presented in [70], in which the thermal history of a component manufactured in the SLM process is modelled. The differential equation of heat conduction is discretized using finite differences and it is solved implicitly. The convection boundary condition is used for the surfaces of the part and a Gaussian profile is used for the laser heating. The moving of the laser heat source is simulated by changing the heating boundary condition over time. Also, the melting phase is taken into account, using the apparent heat capacity method and the material thermal properties are functions of both temperature and porosity. The analysis takes place in 2D, however, a calibration strategy of the model is presented for thin walled 3D parts. Finally, an algorithm which combines node birth and node distance adaptation over time is utilized in order to simulate the addition of new layers of while minimizing the computational time and cost, leading to upto 25 times faster computational times in comparison to standard node birth implementations. The model is capable of providing the temperature profile of the part during the whole manufacturing process, as well as the dimensions of the melt-pool, even when using a standard personal computer. This model can be utilized for process optimization and, with further optimization, for process control as well. In Figure 17, a plot of the simulation of the temperature profile and the melt pool dimensions on the cross-section of the melt pool are depicted.

\section{Discussion}

In Section 2, modelling studies have been presented for each AM process along with the process parameters used and the modelled KPIs. In order to summarize the presented studies, the different KPIs have been classified in groups and the following table has been created. It has to 


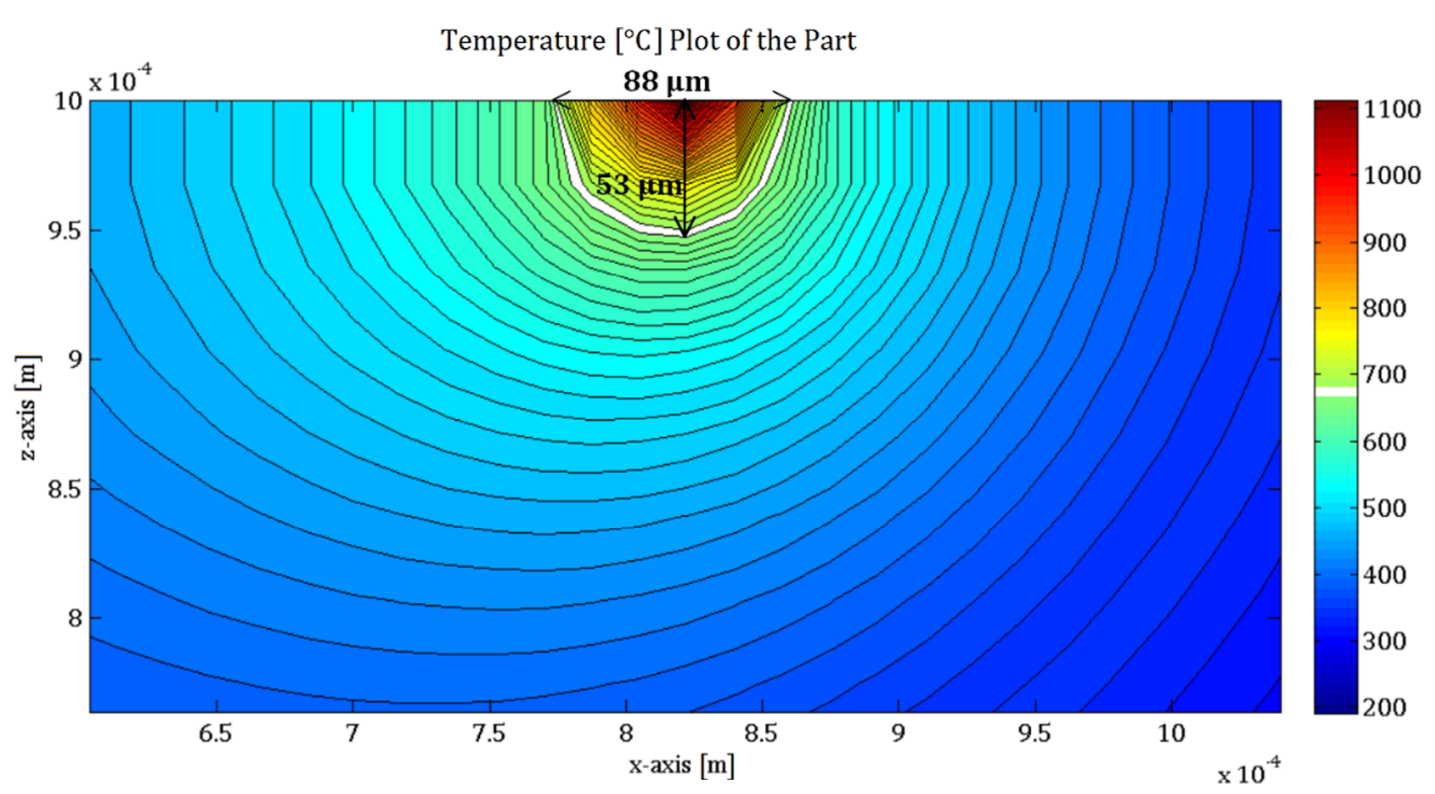

Fig. 17. Temperature profile and melt pool dimensions on the cross-section of the melt pool [70].

be noted that the classification into KPI groups is indicative and that some groups are very closely connected to each other, rendering difficult the choice of a category for the study of modelling. The KPI groups can be seen in the horizontal axis of Table 13, whereas the AM process groups are situated in the vertical axis. Also, a color coding has been used in order to indicate the modelling approach that has been followed in each work (black: analytical, red: numerical, blue: empirical).

More specifically, in this table the state of the art on modelling of AM processes that has been presented in this paper is summarized and classified according to (i) AM process, (ii) Modelled KPI, (iii) Modelling approach. The data of Table 13 have also been graphically presented in Figure 18, in which the percentages of studies that model the different KPI Groups of each AM process group are depicted and in Figure 19, in which emphasis is given in the number of studies that follow a certain modelling approach for the modelling of the different KPI groups.

It can be observed that in each process group different KPIs are those to which the majority of studies refer to. It can be said that, for that particular process group, those KPIs are more significant than the others. In VP, most of the studies model the mechanical properties and microstructure KPIs. In SLS most models refer to heat transfer related KPIs/phenomena, as well as in SLM and EBM, whereas in DED they are one of the two most important categories. In the aforementioned process groups, important also are the dimensional accuracy and microstructure KPIs, which are directly connected to thermal phenomena, as has been previously stated. Also, in the DED process, the droplet kinematics KPI plays a major role, whereas in MJ it is the most modelled one. In ME and UC, the mechanical properties and microstructure KPIs are the ones to which most of the studies refer to. Finally, in BJ the topology/ dimensional accuracy and surface roughness share most of the research interest, as well as in LOM, in which surface roughness, mechanical properties and microstructure and heat transfer related KPIs/phenomena are the three most modelled KPIs. The fact that in each process group the KPIs that attract the highest research interest are different is due to the high importance of that particular KPI for that process group. More specifically, this KPI can be crucial to the process mechanism, encompassing the drawbacks of the process and a model capable of accurately simulating it, can be utilized for the improvement of the important drawbacks of each process group.

An observation concerning the strengths and weaknesses of the different modelling approaches has also been made. More specifically, analytical approaches are fast to run and provide an overview of the physics of the process, however, they tend to require more assumptions and simplification of the process. They are ideal for the modelling of KPIs, like build time and energy consumption, which are easily analytically calculated.

On the other hand, the use of empirical methods requires minimal simplifications and assumptions and leads to direct and validated conclusions. However, there is little to no connection to the physics of the process and the conclusions that are drawn from such models cannot be generalized, since they are directly dependent on the specific conditions of the model calibration experiments that were conducted. As a result, using such methods can be very practical for the solution of a specific problem, but they are unsuitable for the extraction of generalized conclusions concerning the identification and optimization of the problems faced by AM technology. Finally, the use of the numerical approach requires less assumptions than the analytical one, which leads to more realistic models, while it simultaneously provides an overview of the physics of the process. Moreover, models that use this approach are capable of describing not only the initial and final state of the simulated KPI, but also the progression of its values over time, the knowledge of which is of crucial importance for the problem detection and optimization of the process. However, the fact that the phenomena that take place in 
Table 13. KPI groups (horizontal axis) of the different AM process groups (vertical axis) modelled using analytical (black), numerical (red) and empirical (blue) approach.

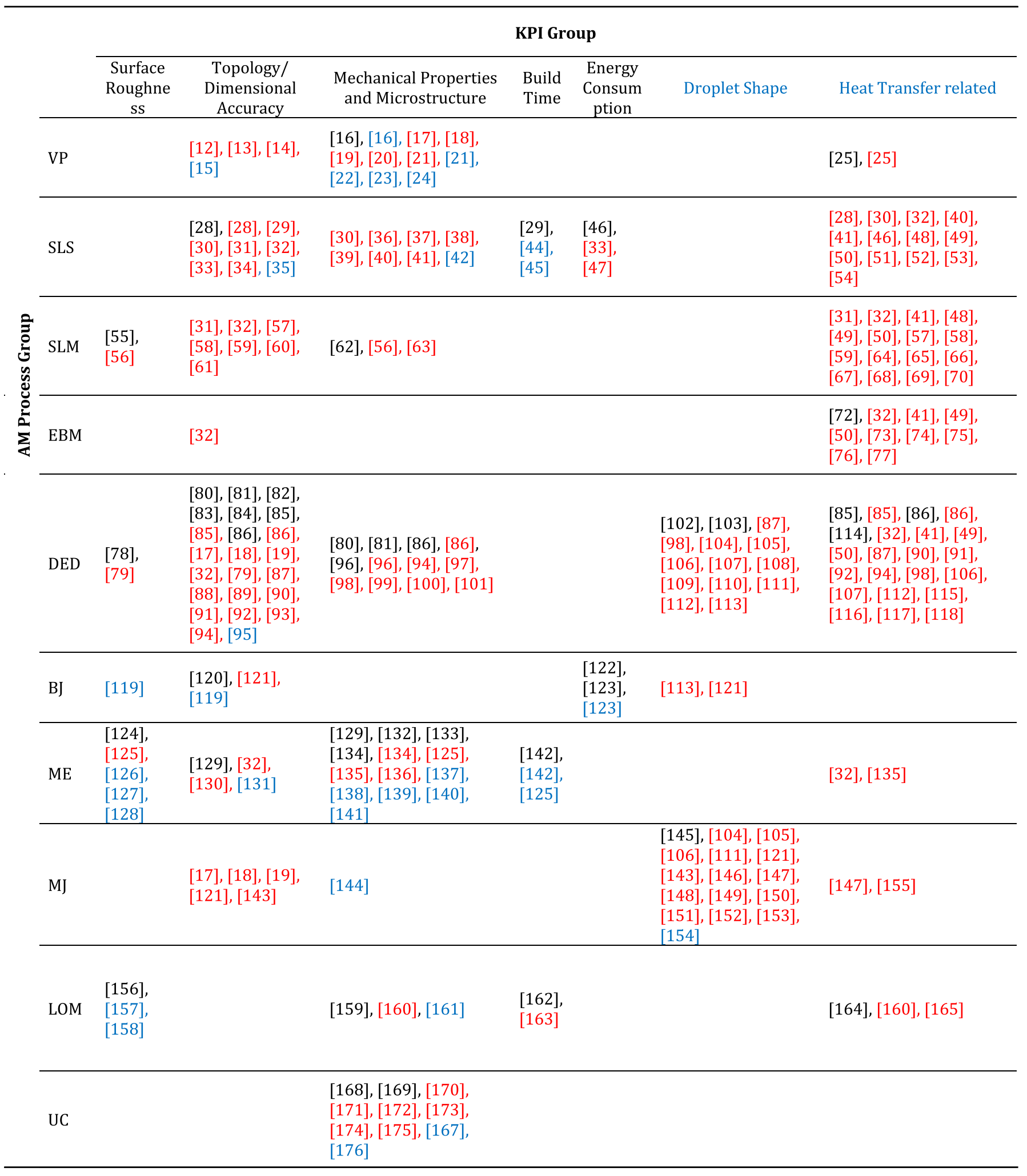




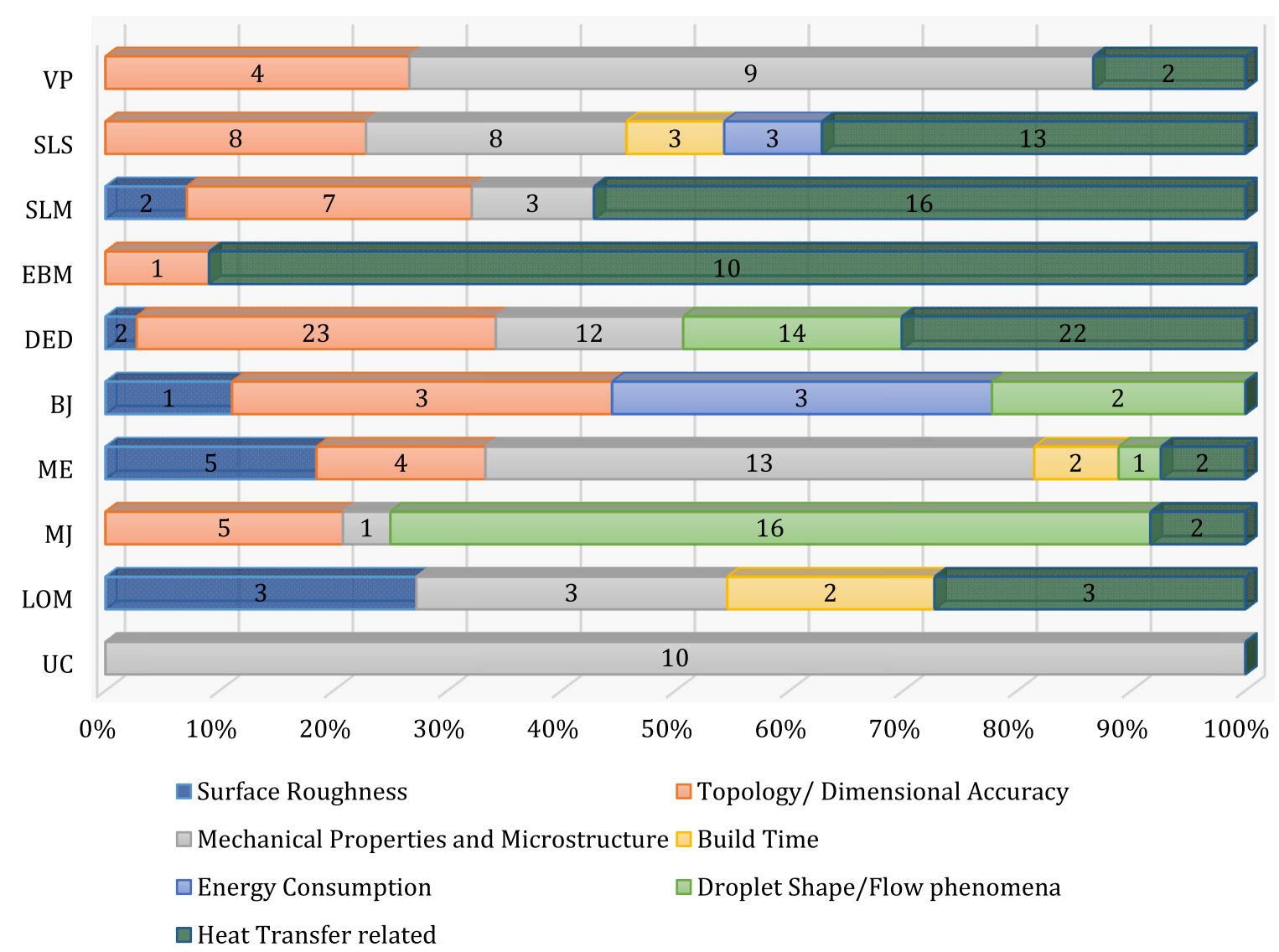

Fig. 18. Percentages of studies that model the different KPI Groups of each AM process group.

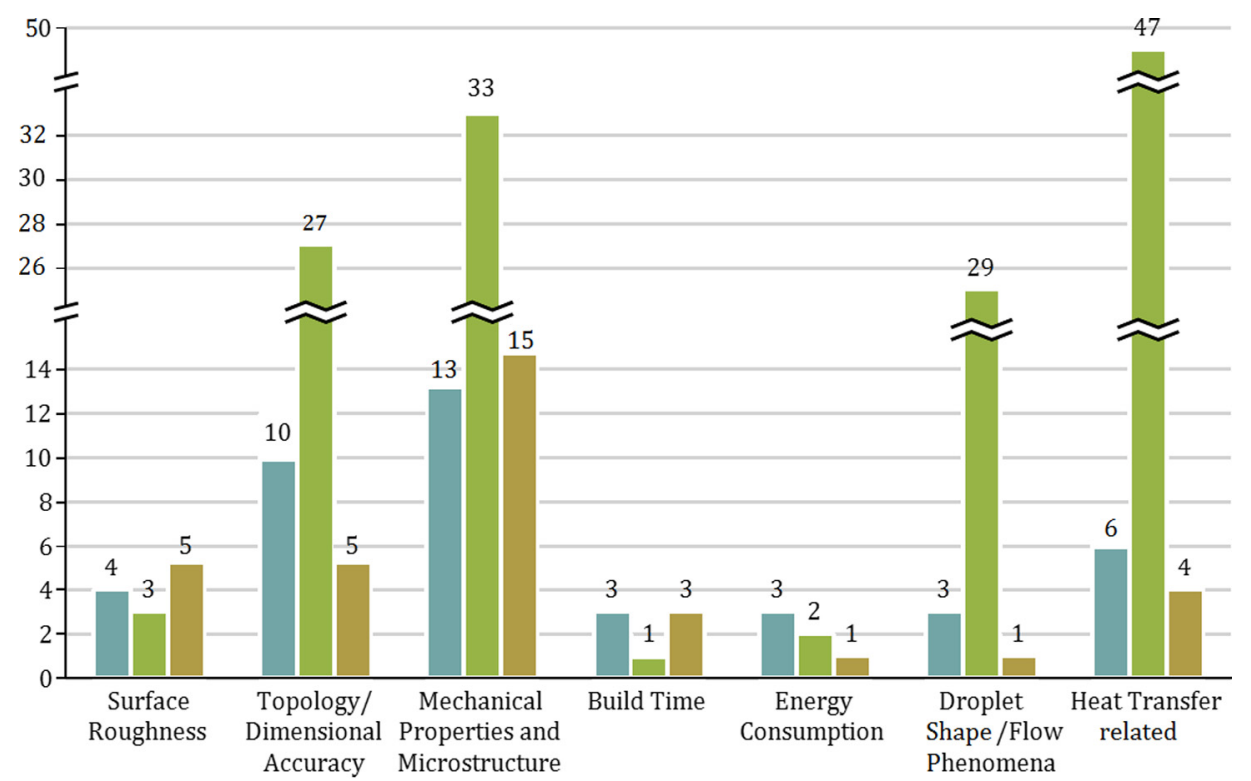

Analytical Numerical Empirical

Fig. 19. Number of studies that follow a certain modelling approach for the modelling of the different KPI Groups. 
AM are highly dynamic both spatially and temporally lead to restrictions concerning the time span and part dimensions that can be modelled when the numerical approach is used, because the computational cost and time needed is extremely high.

Observing Figure 19, it can be seen that a certain modelling approach is preferred by the majority of the studies of each KPI group. This can be attributed to the fact that the different phenomena are more easily described utilizing a certain approach, whereas it is difficult to use the other approaches due to the nature of the KPI. As a result, a connection can be identified between the KPI groups and the modelling approaches: since some KPIs are more easily modelled using a certain approach, the strengths and weaknesses of the modelling approach also characterize the modelling of that KPI as well. More specifically, one of the major drawbacks of numerical modelling is the need of high computational power and of long computational times. Since the KPI groups of droplet kinematics, mechanical properties and microstructure and topology/dimensional accuracy and heat transfer related KPIs are better suited to be modelled using numerical methods, as can be observed in Figure 19, the modelling of those KPI groups faces the same drawbacks to those of the modelling approach that is best suited for the modelling of that group. However, since each approach has different strengths and weaknesses, it is important that modelling studies which utilize different approaches to be available for all the KPI groups and AM processes. This will lead to models of the same KPI that will, however, have different strong and weak points and as a result can be used in conjunction with each other, so as to minimize the weaknesses and maximize the advantages of such an approach. In this scope, Table 13 can be utilized for the identification of those gaps in literature, in order to be addressed by future studies.

\section{Outlook}

In this study the existing literature on process modelling of $\mathrm{AM}$ processes has been presented and classified according to the (i) AM process, (ii) Modelled KPI, (iii) Process parameters used and (iv) Modelling approach followed; also, the gaps in the existing literature concerning the modelling approach used for the different KPI groups and AM processes have been depicted in Table 13 and in Figures 18 and 19.

Moreover, the following conclusion has been drawn concerning the suggested scope future modelling works should follow, so as to better cope with and help in the solution of the problems that are faced by AM today. More specifically, since most of the AM processes utilize heating as a form of bonding of new layers, the modelling of heat transfer related KPIs/phenomena is of crucial importance, because it directly affects the dimensional accuracy, topology, mechanical properties and microstructure of parts. Those are the KPI groups that mainly need to be improved in order to increase the quality of parts manufactured using AM. The complexity and coupling of those KPI groups constitutes the numerical approach as the most suitable one for their modelling, because it needs less assumptions than analytical methods, while it provides an overview of the physics of the whole duration of the process, including the transitional states which are of crucial importance. Also, significant is the fact that they are not dependent to any the specific experimental conditions, like empirical models do, and as a result they can be utilized as tools for the optimization of the process itself. However, the fact that the thermal phenomena that take place in AM processes are highly dynamic in time and space leads to restrictions concerning the time span and part dimensions that can be modelled. As a result, most of the existing modelling approaches are capable of simulating only a short time span of the manufacturing process, or a small section of a part due to the computational cost and time needed for such simulations. However, the knowledge of the entire progression of the phenomenon (thermal history, thermal stresses, thermal distortions) will enable the best possible optimization of the KPIs of the process, as well as provide a tool that can also be used for the optimization of the path planning of the heat source, which will lead to further improvements in the part quality.

Consequently, in order to address some of the most important issues hindering AM today, smarter numerical models, capable of providing accurate calculations of the thermal history and the oversizing of the printed parts, while minimizing the necessary computational costs (time and memory), have to be created. Such models will enable the selection of the process parameters that will maximize the quality of the produced parts, along with providing the necessary information for the optimization of the processes themselves.

\subsection{Implications and Influences}

As a review, this study identifies the most important problems of each AM process group and covers a wide range of modelling approaches, which aim at addressing them. In this regard, it can form a helpful reference, which can be quickly consulted, due to the simple table-based structure classification that has been used. More specifically, it (i) provides important feedback to problems and challenges that have been addressed so far in AM, (ii) highlights literature gaps and (iii) suggests approaches for future modelling studies.

\section{References}

1. ASTM Standard, Standard terminology for additive manufacturing technologies, vol. 10. 04

2. H.A. Hegab, Manuf. Rev. 3 (2016) 11

3. P. Bartolo, J.P. Kruth, J. Silva, G. Levy, A. Malshe, K. Rajurkar, M. Leu, CIRP Ann.-Manuf. Technol. 61 (2012) 635-655

4. G.N. Levy, R. Schindel, J.P. Kruth, CIRP Ann.-Manuf. Technol. 52 (2003) 589-609

5. N. Hopkinson, R. Hague, P. Dickens, Rapid manufacturing: an industrial revolution for the digital age, John Wiley and Sons, New Jersey, 2006

6. T. Caffrey, T.T. Wohlers, Wohlers Report 2015, Wohlers Associates, 2015 
7. H. Bikas, P. Stavropoulos, G. Chryssolouris, Int. J. Adv. Manuf. Technol. 83 (2016) 389-405

8. G. Chryssolouris, Manufacturing systems: theory and practice, Springer Science and Business Media, Berlin, 2013

9. G.N. Levy, Phys. Procedia 5 (2010) 65-80

10. M.D. Monzón, Z. Ortega, A. Martínez, F. Ortega, Int. J. Adv. Manuf. Technol. 76 (2015) 1111-1121

11. I. Gibson, D. Rosen, B. Stucker, Additive manufacturing technologies: 3D printing, rapid prototyping, and direct digital manufacturing, Springer, Berlin, 2014

12. R. Hague, P.M. Dickens, in: D. Bourell (Ed.), Proceedings of the Solid Freeform Fabrication Symposium, University of Texas, Austin, 1996, pp. 523-538

13. R.A. Harris, H.A. Newlyn, R.J. Hague, P.M. Dickens, Int. J. Mach. Tools Manuf. 43 (2003) 879-887

14. K. Xu, T.H. Kwok, Z. Zhao, Y. Chen, J. Comput. Inf. Sci. Eng. 17 (2017) 021012

15. G. Chryssolouris, J. Kotselis, P. Koutzampoikidis, S. Zannis, D. Mourtzis, in: Proceeding of The 32nd CIRP International Seminar on Manufacturing Systems, Leuven, 1999, pp. 213218

16. Y. Abouliatim, T. Chartier, P. Abelard, C. Chaput, C. Delage, J. Eur. Ceram. Soc. 29 (2009) 919-924

17. D. Adalsteinsson, J.A. Sethian, J. Comput. Phys. 120 (1995) 128-144

18. D. Adalsteinsson, J.A. Sethian, J. Comput. Phys. 122 (1995) 348-366

19. D. Adalsteinsson, J.A. Sethian, J. Comput. Phys. 138 (1997) $193-223$

20. N. Hopkinson, P. Dickens, Int. J. Prod. Res. 38 (2000) $3747-$ 3757

21. F. Liravi, S. Das, C. Zhou, Comput.-Aided Des. 69 (2015) 134-142

22. B.S. Raju, U.C. Shekar, K. Venkateswarlu, D.N. Drakashayani, Procedia Technol. 14 (2014) 380-389

23. K. Chockalingam, N. Jawahar, U. Chandrasekar, K.N. Ramanathan, J. Mater. Process. Technol. 208 (2008) 348365

24. B.S. Raju, U.C. Sekhar, D.N. Drakshayani, Procedia Mater. Sci. 5 (2014) 2532-2541

25. M.M. Emami, F. Barazandeh, F. Yaghmaie, J. Mater. Process. Technol. 219 (2015) 17-27

26. J.P. Kruth, P. Mercelis, J. Van Vaerenbergh, L. Froyen, M. Rombouts, Rapid Prototyp. J. 11 (2005) 26-36

27. J.P. Kruth, G. Levy, F. Klocke, T.H.C. Childs, CIRP Ann.Manuf. Technol. 56 (2007) 730-759

28. T.H.C. Childs, M. Berzins, G.R. Ryder, A. Tontowi, J. Eng. Manuf. 213 (1999) 333-349

29. S.H. Choi, S. Samavedam, Comput. Ind. 47 (2002) 39-53

30. F.R. Liu, Q. Zhang, W.P. Zhou, J.J. Zhao, J.M. Chen, J. Mater. Process. Technol. 212 (2012) 2058-2065

31. P. Mercelis, J.P. Kruth, Rapid Prototyp. J. 12 (2006) 254265

32. M.P. Mughal, H. Fawad, R. Mufti, Acta Mech. 183 (2006) 61-79

33. A. Franco, M. Lanzetta, L. Romoli, J. Clean. Prod. 18 (2010) $1722-1730$

34. X.C. Wang, T. Laoui, J. Bonse, J.P. Kruth, B. Lauwers, L. Froyen, Int. J. Adv. Manuf. Technol. 19 (2002) 351-357

35. N. Raghunath, P.M. Pandey, Int. J. Mach. Tools Manuf. 47 (2007) 985-995

36. F.R. Liu, C. He, J.M. Chen, Int. J. Mach. Tools Manuf. 65 (2013) 22-28
37. J.D. Williams, C.R. Deckard, Rapid Prototyp. J. 4 (1998) 90-100

38. S. Eshraghi, S. Das, Acta Biomater. 8 (2012) 3138-3143

39. P. Clementz, J.N. Pernin, Int. J. Eng. Sci. 41 (2003) 23052333

40. P. Peyre, Y. Rouchausse, D. Defauchy, G. Régnier, J. Mater. Process. Technol. 225 (2015) 326-336

41. R. Ganeriwala, T.I. Zohdi, in: D.M.H. Dornfeld (Ed.), Proceedings of the 6th CIRP International Conference on High Performance Cutting, Elsevier, Vol. 14, 2014, pp. 299 304

42. A. Wegner, G. Witt, Phys. Procedia 39 (2012) 480-490

43. Y. Khalil, A. Kowalski, N. Hopkinson, Manuf. Rev. 3 (2016) 15

44. J. Munguía, J. Ciurana, C. Riba, Proc. Inst. Mech. Eng. B: J. Eng. Manuf. 223 (2009) 995-1003

45. M. Ruffo, C. Tuck, R. Hague, Int. J. Prod. Res. 44 (2006) $5131-5146$

46. J.C. Nelson, S. Xue, J.W. Barlow, J.J. Beaman, H.L. Marcus, D.L. Bourell, Ind. Eng. Chem. Res. 32 (1993) 23052317

47. R. Paul, S. Anand, J. Manuf. Syst. 31 (2012) 429-437

48. I. Kovaleva, O. Kovalev, I. Smurov, Phys. Procedia. 56 (2014) 400-410

49. P. Michaleris, Finite Elem. Anal. Des. 86 (2014) 51-60

50. I.A. Roberts, C.J. Wang, R. Esterlein, M. Stanford, D. J. Mynors, Int. J. Mach. Tools Manuf. 49 (2009) 916923

51. J. Xing, W. Sun, R.S. Rana, S.M. IEEE, Optik \&minus; Int. J. Light Electron Opt. 124 (2013) 301-304

52. S. Kolossov, E. Boillat, R. Glardon, P. Fischer, M. Locher, Int. J. Mach. Tools Manuf. 44 (2004) 117-123

53. L. Dong, A. Makradi, S. Ahzi, Y. Remond, J. Mater. Process. Technol. 209 (2009) 700-706

54. R.B. Patil, V. Yadava, Int. J. Mach. Tools Manuf. 47 (2007) 1069-1080

55. G. Strano, L. Hao, R.M. Everson, K.E. Evans, J. Mater. Process. Technol. 213 (2013) 589-597

56. C. Qiu, C. Panwisawas, M. Ward, H.C. Basoalto, J.W. Brooks, M.M. Attallah, Acta Mater. 96 (2015) 72-79

57. A.V. Gusarov, I. Yadroitsev, P. Bertrand, I. Smurov, Appl. Surf. Sci. 254 (2007) 975-979

58. C. Li, Y. Wang, H. Zhan, T. Han, B. Han, W. Zhao, Mater. Des. 31 (2010) 3366-3373

59. L.E. Loh, C.K. Chua, W.Y. Yeong, J. Song, M. Mapar, S.L. Sing, D.Q. Zhang, Int. J. Heat Mass Transfer 80 (2015) 288300

60. T.H.C. Childs, C. Hauser, M. Badrossamay, CIRP Ann. Manuf. Technol. 53 (2004) 191-194

61. F.J. Gürtler, M. Karg, K.H. Leitz, M. Schmidt, Phys. Procedia 41 (2013) 881-886

62. M. Shiomi, K. Osakada, K. Nakamura, T. Yamashita, F. Abe, CIRP Annals - Manuf. Technol. 53 (2004) 195-198

63. M. Smith, Z. Guan, W.J. Cantwell, Int. J. Mech. Sci. 67 (2013) 28-41

64. Y. Li, D. Gu, Mater. Des. 63 (2014) 856-867

65. S. Mohanty, J.H. Hattel, Phys. Procedia 56 (2014) 379-389

66. D. Riedlbauer, M. Drexler, D. Drummer, P. Steinmann, J. Mergheim, Comput. Mater. Sci. 93 (2014) 239-248

67. A. V. Gusarov, I. Smurov, Appl. Surf. Sci. 255 (2009) 55955599

68. K. Zeng, D. Pal, C. Teng, B.E. Stucker, Additive Manuf. 6 (2015) 67-73 
69. F. Verhaeghe, T. Craeghs, J. Heulens, L. Pandelaers, Acta Mater. 57 (2009) 6006-6012

70. P. Foteinopoulos, A. Papacharalampopoulos, P. Stavropoulos, CIRP J. Manuf. Sci. Technol. (2017), DOI: https:// doi.org/10.1016/j.cirpj.2017.09.007

71. X. Gong, T. Anderson, K. Chou, in: Proceedings of the ASME/ISCIE 2012 International Symposium on Flexible Automation, American Society of Mechanical Engineers, St. Louis, 2012, pp. 507-515

72. K. Kanaya, S. Okayama, J. Phys. D: Appl. Phys. 5 (1972) 43

73. M. Markl, R. Ammer, U. Ljungblad, U. Rüde, C. Körner, Procedia Comput. Sci. 18 (2013) 2127-2136

74. J. Romano, L. Ladani, J. Razmi, M. Sadowski, Additive Manuf. 8 (2015) 1-11

75. B. Cheng, S. Price, J. Lydon, K. Cooper, K. Chou, J. Manuf. Sci. Eng. 136 (2014) 061018

76. R. Ammer, M. Markl, U. Ljungblad, C. Körner, U. Rüde, Comput. Math. Appl. 67 (2014) 318-330

77. D. Riedlbauer, T. Scharowsky, R.F. Singer, P. Steinmann, C. Körner, J. Mergheim, Int. J. Adv. Manuf. Technol. 88 (2016) 1309-1317

78. M. Gharbi, P. Peyre, C. Gorny, M. Carin, S. Morville, P. Le Masson, D. Carron, R. Fabbro, J. Mater. Process. Technol. 213 (2013) 791-800

79. S. Morville, M. Carin, P. Peyre, M. Gharbi, D. Carron, P. Le Masson, R. Fabbro, J. Laser Appl. 24 (2012) 032008

80. M.N. Ahsan, C.P. Paul, L.M. Kukreja, A.J. Pinkerton, J. Mater. Process. Technol. 211 (2011) 602-609

81. J. Lin, Opt \& Laser Technol. 31 (1999) 233-238

82. C. Lalas, K. Tsirbas, K. Salonitis, G. Chryssolouris, Int. J. Adv. Manuf. Technol. 32 (2007) 34-41

83. K. Salonitis, A. Stournaras, P. Stavropoulos, G. Chryssolouris, Int. J. Adv. Manuf. Technol. 40 (2009) 316-323

84. A.J. Pinkerton, L. Li, J. Phys. D: Appl. Phys. 37 (2004) 1885-1895

85. P. Peyre, P. Aubry, R. Fabbro, R. Neveu, A. Longuet, J. Phys. D: Appl. Phys. 41 (2008) 025403

86. M.N. Ahsan, A.J. Pinkerton, Model. Simul. Mater. Sci. Eng. 19 (2011) 055003

87. H. Li, P. Wang, L. Qi, H. Zuo, S. Zhong, X. Hou, Comput. Mater. Sci. 65 (2012) 291-301

88. H.O. Zhang, F.R. Kong, G.L. Wang, L.F. Zeng, J. Appl. Phys. 100 (2006) 123522

89. K. Salonitis, L. D'Alvise, B. Schoinochoritis, D. Chantzis, Int. J. Adv. Manuf. Technol. 85 (2015) 2401-2411

90. J. Ding, P. Colegrove, J. Mehnen, S. Williams, F. Wang, P. S. Almeida, Int. J. Adv. Manuf. Technol. 70 (2014) 227-236

91. E. Foroozmehr, R. Kovacevic, Int. J. Adv. Manuf. Technol. 51 (2010) 659-669

92. T. Mukherjee, W. Zhang, T. DebRoy, Comput. Mater. Sci. 126 (2017) 360-372

93. H.M. Chae, Ph.D. thesis, University of Michigan, Michigan, USA, 2013

94. S. Ghosh, J. Choi, J. Laser Appl. 17 (2005) 144-158

95. J. Xiong, G. Zhang, J. Hu, Y. Li, Int. J. Adv. Manuf. Technol. 69 (2013) 743-751

96. A. Crespo, in: A. Ahsan (Ed.) Modelling of heat transfer and phase transformations in the rapid manufacturing of titanium components, INTECH Open Access Publisher, London, United Kingdom, 2011

97. A. Crespo, A. Deus, R. Vilar, in: Proceedings of the XVII International Symposium on Gas Flow and Chemical Lasers and High Power Lasers, Lisboa, 2008, pp. 713120-713121
98. A. Kumar, S. Ghosh, B.K. Dhindaw, Acta Mater. 58 (2010) $122-133$

99. L. Costa, R. Vilar, T. Reti, A.M. Deus, Acta Mater. 53 (2005) 3987-3999

100. J. Yang, F. Wang, Int. J. Adv. Manuf. Technol. 43 (2009) 1060-1068

101. F. Kong, H. Zhang, G. Wang, in: Proceedings of the Progress in Electromagnetics Research Symposium, Beijing, 2009, pp. 946

102. S. Shakeri, S. Chandra, Int. J. Heat. Mass Transf. 45 (2002) $4561-4575$

103. R. Dhiman, S. Chandra, Int. J. Heat Mass Transf. 48 (2005) 5625-5638

104. M. Bussmann, S. Chandra, J. Mostaghimi, Phys. Fluids 12 (2000) 3121-3132

105. W. Zhou, D. Loney, F.L. Degertekin, D.W. Rosen, A.G. Fedorov, AIChE J. 59 (2013) 3071-3082

106. V.D. Fachinotti, A. Cardona, B. Baufeld, O. Van der Biest, Acta Mater. 60 (2012) 6621-6630

107. J.M. Waldvogel, D. Poulikakos, Int. J. Heat Mass Transf. 40 (1997) 295-309

108. M. Pasandideh-Fard, S. Chandra, J. Mostaghimi, Int. J. Heat Mass Transf. 45 (2002) 2229-2242

109. L.U.O. Jun, L.H. Qi, L. Li, Y.A.N.G. Fang, X.S. Jiang, Trans. Nonferrous Metals Soc. China 18 (2008) 686-690

110. D.W. Tian, C.Q. Wang, Y.H. Tian, Trans. Nonferrous Metals Society of China 18 (2008) 1201-1208

111. T. Lim, S. Han, J. Chung, J.T. Chung, S. Ko, C.P. Grigoropoulos, Int. J. Heat Mass Transf. 52 (2009) 431441

112. M. Pasandideh-Fard, R. Bhola, S. Chandra, J. Mostaghimi, Int. J. Heat Mass Transf. 41 (1998) 2929-2945

113. S.D. Aziz, S. Chandra, Int. J. Heat Mass Transf. 43 (2000) 2841-2857

114. A.J. Pinkerton, J. Phys. D: Appl. Phys. 40 (2007) 7323

115. S.M. Kelly, S.L. Kampe, Metall. Mater. Trans. A 35 (2004) 1869-1879

116. H. Qi, J. Mazumder, H. Ki, J. Appl. Phys. 100 (2006) 024903

117. X. Bai, H. Zhang, G. Wang, Int. J. Adv. Manuf. Technol. 69 (2013) 1087-1095

118. X. Bai, H. Zhang, G. Wang, Int. J. Adv. Manuf. Technol. 77 (2015) 717-727

119. H. Chen, Y.F. Zhao, Rapid Prototyp. J. 22 (2016) 527-538

120. J. Moon, J.E. Grau, V. Knezevic, M.J. Cima, E.M. Sachs, J. Am. Ceramic Soc. 85 (2002) 755-762

121. E. Sachs, E. Vezzetti, J. Mater. Process. Technol. 161 (2005) 509-515

122. T Peng in: G. Seliger, Prof. H. Kohl, J. Mallon (Eds.), Proceedings of the $13^{\text {th }}$ Global Conference on Sustainable Manufacturing - Decoupling Growth from Resource Use, Elsevier, 2016, pp. 62-67

123. X. Xu, S. Meteyer, N. Perry, Y.F. Zhao, Int. J. Prod. Res. 53 (2015) 7005-7015

124. D. Ahn, J.H. Kweon, S. Kwon, J. Song, S. Lee, J. Mater. Process. Technol. 209 (2009) 5593-5600

125. K. Thrimurthulu, P.M. Pandey, N.V. Reddy, Int. J. Mach. Tools Manuf. 44 (2004) 585-594

126. P.M. Pandey, N.V. Reddy, S.G. Dhande, J. Mater. Process Technolo. 132 (2003) 323-331

127. R. Anitha, S. Arunachalam, P. Radhakrishnan, J. Mater. Process. Technol. 118 (2001) 385-388

128. A. Boschetto, V. Giordano, F. Veniali, Int. J. Adv. Manuf. Technol. 67 (2013) 2727-2742 
129. A. Boschetto, L. Bottini, Int. J. Advanced Manuf. Technol. 73 (2014) 913-928

130. Y. Zhang, K. Chou, Proc. Inst. Mech. Eng. Part B: J. Eng. Manuf. 222 (2008) 959-968

131. A.K. Sood, R.K. Ohdar, S.S. Mahapatra, Mater. Des. 30 (2009) 4243-4252

132. D. Croccolo, M. De Agostinis, G. Olmi, Comput. Mater. Sci. 79 (2013) 506-518

133. C. Bellehumeur, L. Li, Q. Sun, P. Gu, J. Manuf. Process. 6 (2004) 170-178

134. J.F. Rodríguez, J.P. Thomas, J.E. Renaud, Rapid Prototyp. J. 9 (2003) 219-230

135. Y. Zhang, Y.K. Chou, Proc. Inst. Mech. Eng. Part B: J. Eng. Manuf. 220 (2006) 1663-1671

136. N. Mostafa, H.M. Syed, S. Igor, G. AndrewTsinghua, Sci. Technol. 14 (2009) 29-37

137. S.H. Ahn, M. Montero, D. Odell, S. Roundy, P.K. Wright, Rapid Prototy. J. 8 (2002) 248-257

138. A.K. Sood, R.K. Ohdar, S.S. Mahapatra, J. Adv. Research 3 (2012) 81-90

139. A.K. Sood, R.K. Ohdar, S.S. Mahapatra, Mater. Des. 31 (2010) 287-295

140. A.K. Sood, A. Equbal, V. Toppo, R.K. Ohdar, S.S. Mahapatra, CIRP J. Manuf. Sci. Technol. 5 (2012) 48-54

141. B.H. Lee, J. Abdullah, Z.A. Khan, J. Mater. Process. Technol. 169 (2005) 54-61

142. G. Komineas, P. Foteinopoulos, A. Papacharalampopoulos, P. Stavropoulos, 15th Global Conference on Sustainable Manufacturing, Procedia Manufacturing, Elsevier, Israel, 2017

143. H. Fujimoto, Y. Shiotani, A.Y. Tong, T. Hama, H. Takuda, Int. J. Multiph. Flow 33 (2007) 317-332

144. M. Sugavaneswaran, G. Arumaikkannu, Mater. Des. 54 (2014) 779-785

145. D.Y. Shin, P. Grassia, B. Derby, Int. J. Mech. Sci. 46 (2004) 181-199

146. H.J. Chang, M.H. Tsai, W.S. Hwang, Appl. Math. Model. 36 (2012) 3067-3079

147. P.H. Chen, W.C. Chen, S.H. Chang, Int. J. Mech. Sci. 39 (1997) 683-695

148. P.H. Chen, H.Y. Peng, H.Y. Liu, S.L. Chang, T.I. Wu, C.H. Cheng, Int. J. Mech. Sci. 41 (1999) 235-248

149. N. Nikolopoulos, A. Theodorakakos, G. Bergeles, Int. J. Heat Mass Transf. 50 (2007) 303-319

150. N. Ramakrishnan, P.K. Rajesh, P. Ponnambalam, K. Prakasan, J. Mater. Process. Technol. 169 (2005) 372-381

151. C. Rembe, S. aus der Wiesche, E.P. Hofer, Microelectron. Reliab. 40 (2000) 525-532

152. H. Fujimoto, T. Ogino, H. Takuda, N. Hatta, Int. J. Multiph Flow 27 (2001) 1227-1245

153. H.C. Wu, W.S. Hwang, H.J. Lin, Mater. Sci. Eng. : A 373 (2004) 268-278

154. Y.S. Chen, Y.L. Huang, C. H. Kuo, S.H. Chang, Int. J. Mech. Sci. 49 (2007) 733-740
155. Z. Zhao, D. Poulikakos, J. Fukai, Int. J. Heat Mass Transf. 39 (1996) 2771-2789

156. B.K. Paul, V. Voorakarnam, J. Manuf. Process. 3 (2001) 94 101

157. G. Chryssolouris, J.D. Kechagias, J.L. Kotselis, D.A. Mourtzis, S.G. Zannis, in: Proceedings of the 8th European Conference on Rapid Prototyping and Manufacturing, Nottingham, 1999, pp. 141-152

158. G. Chryssolouris, J.D. Kechagias, J.L. Kotselis, D.A. Mourtzis, S.G. Zannis, in: 8th European Conference on Rapid Prototyping and Manufacturing, Nottingham, 1999, pp. $141-152$

159. A. Das, G. Madras, N. Dasgupta, A.M. Umarji, J. Eur. Ceramic Soc. 23 (2003) 1013-1017

160. F.O. Sonmez, H.T. Hahn, Rapid Prototyp. J. 4 (1998) 26-36

161. G. Chryssolouris, J. Kechagias, P. Moustakas, E. Koutras, CIRP J. Manuf. Sys. 32 (2003) 319-322

162. J. Kechagias, S. Maropoulos, S. Karagiannis, Rapid Prototyp. J. 10 (2004) 297-304

163. A.K. Sridharan, S. Joshi, J. Manuf. Sys. 19 (2001) 355-364

164. L. Flach, A.D. Klosterman, P.R. Chartoff, in: Proceedings of Solid Freeform Fabrication Symposium, 1997, pp. 677688

165. L. Flach, M.A. Jacobs, D.A. Klosterman, R.P. Chartoff, in Proceedings of the Solid Freeform Fabrication Symposium, 1998, pp. 407-416

166. B.G. Mekonnen, G. Bright, A. Walker, in: D. K. Mandal, C. S. Syan, (Eds.) in: Proceedings of the CAD/CAM, Robotics and Factories of the Future, New Delhi, 2016, Springer, India, 2016, pp. 207-216

167. G.J. Ram, Y. Yang, B.E. Stucker, J. Manuf. Sys. 25 (2006) 221-238

168. A. Siddiq, T. El Sayed, Comput. Mater. Sci. 51 (2012) 241-251

169. Y. Yang, G.D. Janaki Ram, B.E. Stucker, Rapid Prototyp. J. 16 (2010) 20-28

170. G.S. Kelly, S.G. Advani, J.W. Gillespie, T.A. Bogetti, J. Mater. Process. Technol. 213 (2013) 1835-1845

171. C.S. Zhang, L. Li, Ultrasonics 50 (2010) 811-823

172. D. Pal, B. E. Stucker, Virtual Phys. Prototyp. 7, (2012) 6579

173. A. Siddiq, E. Ghassemieh, Int. J. Adv. Manuf. Technol. 54 (2011) 997-1009

174. D. Pal, N. Patil, K. Zeng, B. Stucker, J. Manuf. Sci. Eng. 136 (2014) 066102

175. C.Y. Kong, R.C. Soar, P.M. Dickens, Proc. Inst. Mech. Eng., Part C: J. Mech. Eng. Sci. 219 (2005) 83-91

176. C.D. Hopkins, P.J. Wolcott, M.J. Dapino, A.G. Truog, S.S. Babu, S.A. Fernandez, J. Eng. Mater. Technol. 134 (2012) 011004

177. J.O. Wilson, D. Rosen, in: Proceedings of the ASME 2005 International Design Engineering Technical Conferences and Computers and Information in Engineering Conference, American Society of Mechanical Engineers, Long Beach, 2005, pp. 451-460

Cite this article as: Panagiotis Stavropoulos, Panagis Foteinopoulos, Modelling of additive manufacturing processes: a review and classification, Manufacturing Rev. 5, 2 (2018) 